University of Zurich

Department of Economics

Working Paper Series

ISSN 1664-7041 (print)

ISSN 1664-705X (online)

Working Paper No. 154

In search of economic reality under the veil of financial markets

Josef Falkinger

April 2014 


\title{
In search of economic reality under the veil of financial markets*
}

\author{
Josef Falkinger $^{\dagger}$
}

April 15, 2014

\begin{abstract}
This paper presents a general equilibrium model with technological uncertainty, financial markets and imperfect information. The future consists of uncertain environments that are more or less clearly distinguishable (measurable). This limits the possibilities of specialization and diversification. Households have no direct information about the productivity of risky technologies. They rely on the information conveyed by the set of financial products provided by the financial sector, the pay-off promises of the products and their prices. Unreliable information-processing by financial markets leads to deception of households. As a result, extending the space spanned by financial products is not unambiguously good. This suggests a policy rule which ties financial innovations to the experience base of the economy.

Keywords: Real and financial economics, incomplete knowledge, risk and uncertainty, financial crisis, size of financial sector, responsible finance
\end{abstract}

JEL classification: D53, D83, G01, G21, B41

*I wish to thank Timo Boppart, Hartmut Egger, Michel Habib, Markus Knell, Felix Kübler, Jean-Charles Rochet, Martin Summer, Sabrina Studer, Yingnan Zhao and Fabrizio Zilibotti for illuminating discussions on the topics of this paper. I also wish to thank the participants in the Finance seminar at the University of Zürich, seminar participants at Österreichische Nationalbank and at the University of Bayreuth for valuable comments.

${ }^{\dagger}$ University of Zurich, Department of Economics, Zürichbergstrasse 14, CH-8032 Zürich. E-mail: josef.falkinger@econ.uzh.ch 


\section{Introduction}

Most economists would share the view that financial development is an important source of prosperity. At the same time, many people think that the financial sector is responsible for severe crises and misallocations of resources. The strong growth of the financial sector over the last decades (outlined, for instance, in Greenwood and Scharfstein [2013] or Philippon [2013]) has moved the tension between the rival views about financial markets into the core of public debate. This paper contributes to the understanding of the tension by considering the nature of financial markets in a general equilibrium model with technological uncertainty and imperfect information.

The central question is: What are the inputs from the financial sector required by households and firms and how do they affect the economy? For answering the question I focus on the information-processing role of the financial system and ignore other essential functions of financial intermediation like liquidity provision, asset transformation, risk taking or monitoring, as usually considered in the literature on financial intermediation and banking (Cf. Freixas and Rochet [1998;2008]). The information-processing role of markets relies on the price system as a communication mechanism, as Hayek [1945] pointed out in his pioneering work. According to Fama [1970], "the ideal is a market in which ... security prices at any time "fully reflect" all available information" (p. 383). This paper is silent on whether or not financial markets are ideal in this sense 1 Prices may convey more or less reliable

\footnotetext{
${ }^{1}$ Without doubt the growth of the financial sector has been accompanied by an enormous increase in the number of financial products and prices. Nonetheless, there is no consensus that the information-processing quality of financial markets has improved. Bai, Philippon and Savov [2013], for instance, find no evidence for increased information con-
} 
information - be it that they are not ideal or because they deal with circumstances about which little reliable information is available to begin with.2 In any case, the prices have real consequences. This paper contributes to the understanding of that consequences. In other words, the paper focuses on the user side in Hayek's [1945] communication channel in which "the knowledge of the circumstances of which we must make use" (p. 519) is produced by the price formation process that communicates "the information which is in fact dispersed among all the people involved in the process" (p. 526). Who are "the people involved in the [price formation, JF] process" and who are the ones that "must make use" of the information conveyed by the prices? In this paper, which deals with the information-processing role of financial product prices, the active part is played by the agents in the financial sector and the user part is played by the households and firms 3

In sum, the perspective on financial markets taken in this paper is an outsider's one who sees the nature of economic reality from the following bird's eye view. Economic objects are "things" with a price tag showing their valuation by the market. Financial markets attach to things today their value for the future. The future however results from saving and investment today, when the future is a set of ideas rather than realised things. What is then reality and what is the role of financial markets in shaping real-

\footnotetext{
tent over the past fifty years

${ }^{2}$ In Hirshleifer's [1971] words, if things are "hidden from view" and have still to wait for "discovery".

${ }^{3}$ In this respect, the spirit of the paper is related to the review of Bond, Edmans and Goldstein [1912] (see also Bay, Philippon and Savov [2013]). Their focus, however, is on the interaction between financial markets and firm decisions, whereas my work takes a macroeconomic perspective and concentrates mainly on the consequences of financial markets for the households' savings decisions and future consumption possibilities.
} 
ity? According to this paper, the basic function of the financial system is to provide means to express and exchange promises - financial products and to convey information about future possibilities by pricing the products. Households and firms need these means for transforming ideas about future possibilities into realised possibilities. Volume and reliability of information conveyed by the financial products and their prices determine the success of the transformation. In particular, if the provision of financial products is based on unreliable information, consumption plans may be deceived. As a consequence, financial innovations are not necessarily a good thing.

In the further two sections of the introduction, first the modeling principles and primitives of the analysis are described, then the specific contributions of the analysis and their relation to the literature are outlined.

\subsection{Modeling principles and primitives}

The following traits of life in a modern economy are taken as facts. Fact 1: The future is partly "men-made" and partly depends from exogenous forces ("nature"). Fact 2: The future is uncertain and there is limited knowledge about the possible realizations of future events. Fact 3: There are two sources of information - direct inspection of fundamentals and inference from market data. Fact 4: In a complex economic system, individuals act in specialized roles. In particular, there is specialization in the collection and transmission of information.

From these facts three basic requirements follow for the transformation of current resources to future possibilities and its modeling. Requirement 1 
("Measurability"): State-contingent resource transformation from present to the future is only possible for measurable states. Therefore, the modeling of the state space and its measure is one crucial element in the analysis of this paper. Requirement 2 ("Real investment"): Present-day household income can only be saved for future consumption if firms invest the savings in future production possibilities. The second important element in the presented model is therefore the set of possible technologies and their statecontingent performance. Requirement 3 ("Financial intermediation"): The investment of household savings into future production possibilities of firms requires instruments for expressing and exchanging promises; whereas the saved resources have to be given away today, the output from the created production possibilities accrues tomorrow. The instruments for expressing and exchanging promises are modeled as financial products characterized by state-contingent pay-offs. They are designed and priced by financial agents who collect and aggregate information (about future possibilities and their risks) by inspection of fundamentals and arbitrage trade.

In sum, the possibilities to transform resources from present to an uncertain future depend on three objects: the set of measurable states, the set of possible technologies and the set of financial products. Whereas the allocation of resources to future possibilities is decided today - on the basis of the information conveyed by the financial products, the realization of possibilities takes place in the future. The extent to which future reality matches the promises of today depends on the information-processing quality of the financial system. Thus, if financial agents are careless, they exert a negative externality on households 4

\footnotetext{
${ }^{4}$ In this respect the presented model is related to Magill, Quinzii and Rochet [2013] who consider a complete market model in which all possible future outcomes are insurable
} 


\subsection{Specific contributions and relation to literature}

A first contribution concerns uncertainty. Standard economic reasoning thinks about the future as an event space, $\Omega$, with a probability measure, $\pi$, assigning to each event in $\Omega$ the probability of its realization. However, as Keynes and Knight most prominently pointed out, uncertainty cannot be fully reduced to measurable risk. More recent contributions to the foundations of economic decision making under uncertainty have picked up this issue by modeling Knightian uncertainty as uncertainty about the probability distribution, where the uncertainty about the latter is captured by characterizing the set of possible distributions (see for instance Gilboa and Schmeidler [1989] or Bewley [2002]) 5 In the baseline model, this paper follows the more radical view of "true uncertainty", which Keynes [1937, p. 214] summarized by the phrase:"We simply do not know." I account for the principle limits of knowledge by splitting the future event space into two sets: a subset $S$ of measurable risks, which in principle can be insured by state-contingent securities, and a subset $\bar{S}$ which is not measurable. In addition, I also consider Knightian uncertainty by allowing the measure on $S$ to be more or less precise.

A second contribution concerns the relationship between specialization, diby securities but the risk distribution can be influenced by some agents. Although in the model presented here neither true probabilities nor true productivities can be influenced, future production and output will be distorted if the beliefs about probabilities and productivities conveyed by the price and pay-off structure of the traded financial products are inaccurate.

${ }^{5}$ See also the notion of model misspecification and robustness (Hansen and Sargent [2007]) or the literature on ambiguity following Ellsberg [1961] (see, for instance, CerreiaVioglio et al. [2013]). 
versification and robustness. The diversification possibilities provided by financial markets depend on the state-contingent performance of the technologies in which savings are invested. Thus, the degree of completeness changes if more specialized technologies become feasible by innovation. As Diamond [1967] pointed out, there is an important informational aspect which limits these possibilities of market completion, namely, "an inability to distinguish finely among the states of nature in the economy's trading" (p. 760). The limit is reflected in the presented model in two ways: First, the unmeasurability of $\bar{S}$ expresses in a formal way that events within $\bar{S}$ are not distinguishable 6 Second, the measure $\pi$ on $S$ (the measurable part of $\Omega$ ) may be imprecise. On top of the principle constraints on the measurability of events (or the precision of the measure), knowledge about the performance of a technology in a specific environment may be imperfect, too. Ultimately, there exist two possibilities to insure against future uncertainty. Either the savings are invested into a robust technology which works smoothly under any exogenous conditions; or the savings are diversified across different independent technologies, each of which works well in certain circumstances but not so well under other conditions. The latter is clearly brought out by the paper of Acemoglu and Zilibotti (1997) on risk, diversification and growth 7 In their model diversification is limited by minimum size requirements for innovation. In contrast, in my analysis markets are incomplete because of limited knowledge about the future. As a consequence, financial innovation - allowing households and firms to save in more diversified portfolios and to

\footnotetext{
${ }^{6}$ Formally, $\bar{S}$ is thus a single state so that the state space is given by $S \cup\{\bar{S}\}$.

${ }^{7}$ At the aggregate level, the model presented here essentially coincides with their framework if perfect measuring of risks is assumed, precise knowledge about the technological uncertainty is available, and transaction costs for financial intermediation are set to zero. Yet, neither economic growth nor long-run development are considered here.
} 
invest into more specialized technologies, respectively - is not necessarily a good thing. On the one side, as long as markets are missing in the measurable part of the future, financial innovations that cover additional risks increase diversification possibilities. On the other side, if the new financial products and their prices are based on imprecise information, they generate new uncertainty. This and the uncertainty in the non-measurable part of the future cannot be insured by providing more state-contingent financial instruments. In sum, any innovation based on erroneous measurement of the future generates uninsured uncertainty in the diversified part of savings and investments. As a consequence, the allocation of savings is distorted away from robust technologies to non-performing specialized technologies.

The third contribution concerns the consequences of specialization in the acquisition and dissemination of information. According to the approach of this paper, a specialized intermediation role has emerged - to have expertise for collecting information about fundamentals, coordinating beliefs by arbitrage, and communicating the results in the financial instruments and their prices. In other words, since there are no "invisible hands" or virtual auctioneers who could provide intertemporal financing possibilities at correct prices, "embodied" financial agents act in this function. There are two sources of information: direct inspection of reality and inference from market data. In contrast to most of the literature on the information-processing role of markets 8 in the framework presented here the window of direct inspection

\footnotetext{
${ }^{8}$ Including the literature on crises and belief volatility which has recently emerged. There, information is heterogeneous insofar as different agents receive different private signals. Access to private signals, however, is symmetric in the sense that all agents receive a signal drawn independently from the same distribution (see Angeletos and Werning [2006] for an important example - based on the information structure considered in Morris
} 
is not open equally to all agents. In particular, households cannot directly inspect the state-contingent performance of technologies. Moreover, unlimited arbitrage is only possible for financial agents. 9 These assumptions model the fact that individuals act in specialized roles 10 The agents in the real sectorhouseholds and firms - save in portfolios and invest in specific technologies, respectively; the set of financial instruments they can use, as well as the payoff promises and prices they face, are given by the financial sector: that is, by the aggregate outcome of the direct inspection and arbitrage activities of the financial agents. The activities of the financial agents require resources and Shin [1998]). In Grossman and Stiglitz [1976,1980] only a subset of agents acquires information; yet the subset is randomly drawn and individuals are symmetric ex ante. Symmetric dispersion of information was suggested by Hayek's [1945] view that knowledge "never exists in concentrated or integrated form, but solely as the dispersed bits of incomplete and frequently contradictory knowledge which all the separate individuals process"(p. 519). At the same time, however, he acknowledged that "different kinds of knowledge "are "at the disposal of particular individuals" or "in the possession ... of experts" (p. 521).

${ }^{9}$ There are clearly exemptions. For instance, if a household invests in a house to live in. In general, however, the typical household is not owner or expert of the projects which are financed by her or his savings. Moreover, also households and firms may participate in the financial market for speculative motives. But this is not their core function; if it is, they switched roles.

${ }^{10}$ To think in a model of roles or functions was common in Classical Political Economy (see Schumpeter $[1954 ; 1959$, pp.554-561] on actors and agents - or 'functional classes' in the classic modeling.) Traditional macroeconomics also separates the roles of consumer (or workers) and investors. Moreover, it takes a stand on who plays an active or a passive role in determining aggregate outcomes, as emphasized most clearly by Kalecki (see Laski [1987] for a concise introduction into his work). By contrast, in current economic modeling it has become usual that each individual acts in all roles. This misses the fact that roles emerge in a system to exploit the advantages of specialization. See also Solow [2008] on the importance of accounting for different roles. 
as input. The costs are financed by pay-off differentials for borrowers and lenders 11 Their aggregate value represents the size of the financial sector in terms of GDP. (This holds regardless of whether the incomes of the financial sector include rents or correspond to minimal costs.)

By focusing on the most basic traits of an economy with financial markets the paper disregards many relevant facets of these traits and ignores a lot of important issues. In particular, the paper does not address any monetary or financing aspects (like liquidity or leverage) nor dynamical issues (like herding or financial cycles), which build the core of the current discussion about financial crises and policies to deal with such crises 12 Moreover, it does not explain the allocation of information-processing resources and the production of information within the financial sector. This function is captured by

\footnotetext{
${ }^{11}$ These differentials, working like a tax, are exogenous in the paper. Thus, the presented analysis is silent about whether the financial sector exerts its intermediation function in a cost-efficient way. For a more elaborated analysis of the banking sector in a model with technological uncertainty see Studer [2013]; there, the cost function of banks and competition between banks are explicitly modeled, and financial innovation as well as the size of the banking sector are endogenously determined by the interplay of bank competition and diversification-seeking consumers.

${ }^{12}$ As Geanakoplos [2010] puts it, an important lesson from the current crisis is "that the macro economy is strongly influenced by financial variables beyond prices"(p.6) leverage in his case. Or in Shin's [2007] words: “...the common thread [of the literature on liquidity, JF] is the relationship between funding conditions and the resulting market prices of assets"(p. 317). In a similar vein, Brunnermeier and Sannikov [2014] put financial frictions and the risk created by endogenous amplification of such frictions in the center of their macroeconomic model with a financial sector. See also Borio [2012] on the need to integrate monetary and financing constraints in macroeconomic models - on top of financial intermediation in the allocation of resources between savers and investors - and to consider medium-term financial cycles in addition to business cycles.
} 
assuming that prices and pay-offs of financial products satisfy a no-arbitrage condition. That means, financial markets are successful in coordinating financial agents and aggregating their information and beliefs, but they do not necessarily provide efficient collection of information about fundamentals. The focus of this paper is on the consequences of a given informationprocessing quality of the financial sector for production and consumption. It is complementary to the finance and monetary macroeconomics literature and wants to contribute to the "broad-exploration mode" (Caballero [2010]) of our discipline's thinking.

The paper is organized as follows. In the next section, uncertainty structure, technology and boundaries of knowledge are discussed and formally outlined. Section 3 deals with the role of financial agents and firms. The behavior of households, in particular their saving decision, is analyzed in Section 4. In Section 5, the consequences of unreliable financial prices are considered by comparing planned and realised consumption levels to each other. Section 6 characterizes the size of the financial sector relative to GDP and discusses the quality of the financial sector. Section 7 applies the analysis to a model in which all future events are insurable in principle, but financial innovations come with a cost: unprecise probability assessment. In this way, macroeconomic effects of Knightian uncertainty are analyzed and the meaning of unreliable financial innovations is characterized in a rigorous way. Finally, as an illustration, a rule for the appropriate variety of financial products (in relation to the experience base of the economy) is derived. Section 8 concludes. 


\section{Uncertainty structure, technology and bound- aries of knowledge}

\subsection{Uncertainty structure}

There are two periods of time: Presence, $t=0$, and future, $t=1$. The future is uncertain. Let $\Omega$ be the set of possible future events that are potentially relevant for economic performance. Each $\omega \in \Omega$ describes an exogenous environment that is possibly realised in $t=1$. Because of limited knowledge not all events can be distinguished from each other and measured in a meaningful way. Formally, space $\Omega$ is partitioned into a subspace $S$ and its complement $\bar{S} \equiv \Omega-S$. S can be measured by a probability measure $\pi_{\omega}$, $\sum_{\omega \in S} \pi_{\omega}=1$. No such measure exists on $\bar{S}$. In other words, $\omega \in S$ are the "distinguishable" environments - the states - for which specialized technologies and state-contingent financial products can be designed in principle. No such specialization or diversification is possible within $\bar{S}$. The measure of $S$ and $\bar{S}$ in $\Omega$ is $\mu(S)=\mu, \mu(\bar{S})=1-\mu$

\subsection{Technologies}

The output of the economy consists of one final good which can be used for consumption and investment. The price of this good is set equal to one.

\footnotetext{
${ }^{13} \pi$ and $\mu$ are measures on different fields. Formally, there is a probability space $(S, \mathcal{A}, \pi)$, with $\mathcal{A}$ containing all singletons in $S$, and a probability space $(\Omega,\{\emptyset,\{S\},\{\bar{S}\}, \Omega\}, \mu)$. Note also that unmeasurability of $\bar{S}$ does not imply that agents are unaware of $\bar{S}$ in the sense of Modica and Rusticchini [1999].
} 
Production uses capital as input. I assume that technologies are linear in capital. Moreover, to focus on the role of the financial sector in helping to transform income of today into income tomorrow, it is assumed that capital fully depreciates after production so that only the capital invested in $t=0$ matters as input for production in $t=1$. In $t=1$, all output is consumed and life ends.

There are two types of technologies for producing final output: a robust technology and risky technologies. The robust technology works in any environment. Formally, each unit of physical capital invested into the robust technology generates, for any realization $\omega \in \Omega$, the output $a>0$. In contrast, risky technologies are highly productive, but sensitive to the realised environment. More specifically, each technology works only in a particular environment. In $\bar{S}$ none of them is productive. Formally, for each $s \in S$, there exists a risky technology $s$ with stochastic productivity

$$
\tilde{A}_{s}(\omega)= \begin{cases}A_{\omega} & \text { if } s=\omega \text { and } \omega \in S \\ 0 & \text { otherwise. }\end{cases}
$$

Possible interpretations are, for instance, specialized techniques targeted to clearly specified conditions. No such specialization is possible for the indistinguishable environments in $\bar{S}$.

There is a trade-off between specialization advantage and risk. On the one side, a technology is more productive if it is targeted to a more specific environment - provided that the relevant environment is realised. On the other hand, specific environments are less likely. The trade-off is modeled in the following way. Specialized technologies are generated from a general stock of knowledge, $A$. The productivity of a technology, specialized to a partic- 
ular environment, is inversely related to the probability of the environment. The following condition captures this property of the productivity generating process formally: For all $\omega \in S$,

$$
\pi_{\omega} A_{\omega}=A, \quad \mu A>a .
$$

Conditional on $S$, the expected productivity level of all environment-specific technologies is equal to $A$, the economy's stock of knowledge for highly productive risky projects 14 Moreover, unless $\bar{S}$ is realised, specialized technologies are more productive than the robust technology. It is worth noting that the unconditional expectation of an environment-specific productivity is $\mu A$ since $\omega \in S$ is realised with probability $\mu$. Only share $\mu$ of $A$ is exploitable for environment specific projects 15

\subsection{Knowledge structure}

All agents see the world in the described framework. In general, however, they have imperfect knowledge about the true values of the fundamentals so that their behavior is based on beliefs about the fundamentals. Let $S^{*}, \pi^{*} \equiv$

\footnotetext{
${ }^{14}$ Alternatively, we could read (1) and (2) as follows: There exists risky technologies $s \in S$ which perform with productivity $A_{\omega}$ in a good state and do not deliver output in a bad state. The probability that for a particular technology a good state emerges is inversely related to its productivity level. One further property of specification (2) is worth noting. Rewriting (2) as $\pi_{\omega}=A / A_{\omega}$ and summing over $\omega \in S$, we obtain $A=\left[\sum_{\omega \in S} 1 / A_{\omega}\right]^{-1}$ and $\pi_{\omega}=\left[A_{\omega} \sum_{\omega \in S} 1 / A_{\omega}\right]^{-1}$. Hence, if $A_{\omega}$ is known for all $\omega \in S$, then one can infer $A$ and $\pi_{\omega}$.

${ }^{15}$ If $\pi$ is given by the uniform distribution on $\Omega=[0,1]$ and $A_{\omega}=A$ is assumed, we get the specification used in Acemoglu and Zilibotti [1997], where specialized technologies are available for all $\omega \in \Omega$, but fixed costs limit the range $(\mu)$ of realised technologies (in interaction with market size).
} 
$\left(\pi_{\omega}^{*}\right)_{\omega \in S^{*}}, \mu^{*}$ and $A^{*}, a^{*}$ denote these true values and let $S^{i}, \pi^{i} \equiv\left(\pi_{\omega}^{i}\right)_{\omega \in S^{i}}$, $\mu_{i}, A^{i}$ and $a^{i}$ be the respective beliefs of agent $i$.

There are three types of agents: Households $(N)$, firms $\left(I_{F}\right)$ and financial agents $\left(I_{B}\right)$. They have different access to information about the fundamentals. In particular, households have no direct access to information about the performance of specific technologies in particular environments. This information is spread across firms and aggregated by the financial agents. After all, scale effects in information acquisition about investment projects are the reason why a specialized role of financial intermediation exists according to the approach of this paper. By direct inspection of firms and arbitrage trading the financial agents collect and aggregate information. The arbitrage trading also coordinates beliefs within the financial sector; they are communicated through the market data. The next section discusses this in more detail.

In particular, the set of insurable states can be inferred from the set of financial products supplied. Since a product insuring a state $\omega$ has only a market if households and firms consider $\omega$ as measurable, I assume that the beliefs about $S^{*}$ coincide across agents. That is, there exists $S$ so that

$$
S^{i}=S \text { for all } i \text {. }
$$

Moreover, I assume that all agents have perfect knowledge about the productivity of the robust technology. That is,

$$
a^{i}=a^{*} \text { for all } i \text {. }
$$




\section{Financial markets and capital demand by firms}

Financial agents ("banks") offer two types of financial products: a bond which households and firms can use for lending and borrowing at a fixed interest rate; and, for each $\omega \in S$, an Arrow-security. In reality we have of course more complex financial products. From the abstract point of view of the presented model, however, the essential property of products is their capacity to provide state-contingent savings and financing opportunities. As a consequence, financial innovation - that is, the provision of new financial products - boils down to extending the set $S$ of states for which a security is available. By designing state-contingent financial products, the financial sector informs the market about what is considered as diversificable risk. $S$ may be smaller or larger than $S^{*}$. Since the consequences of $S \supset S^{*}$ are straight-forward - non-honored promises for $\omega \in S-S^{*}$ - we assume $S \subset S^{*}$ in the further analysis. If $S=S^{*}$ is reached, markets are completed with respect to the measurable state space $S^{*} \cup\left\{\bar{S}^{*}\right\}$. As long as there is a nonempty set $\bar{S}^{*}$ of unmeasurable events, however, they remain incomplete with respect to the event space $\Omega$.

Firms use the financial products for financing their capital demand. Households use the products for investing their savings. The conditions for households and firms differ as follows: A firm borrowing in $t=0$ one unit by issuing a bond has to pay $r$ units in $t=1$. In contrast, a household buying a bond in $t=0$ earns

$$
r_{h}=r\left(1-\tau^{-}\right)
$$


units in $t=1$, where $0 \leq \tau^{-}<1$ and $r_{h}>0$. The prices of Arrow-securities are denoted by $\left(q_{\omega}\right)_{\omega \in S}$. The gross pay-offs they promise are $\left(R_{\omega}\right)_{\omega \in S}$. That means, if a firm sells one unit of an $\omega$-security, it receives $q_{\omega}$ units of capital in $t=0$ and has to pay back, in $t=1, R_{\omega}$ units of output, if $\omega$ is realised, and zero otherwise. The corresponding pay-offs for the saving household are

$$
R_{\omega}^{h}=R_{\omega}\left(1-\tau^{+}\right), \quad \omega \in S
$$

with $0 \leq \tau^{+}<1$. It seems reasonable to assume that fees for risky assets are higher than those for bonds, that is: $\tau^{+}>\tau^{-}$.

The aggregate fee volume raised by $\tau^{-}$and $\tau^{+}$constitutes the financial agents income. They are risk-neutral and have unlimited access to funds for exploiting arbitrage opportunities at zero cost. As a consequence, arbitrage trade equalizes expected returns across $\omega$-securities and coordinates beliefs across financial agents. In equilibrium the following property holds.

Property 1. (No-arbitrage condition). There exists $\pi^{b}$ and $R>0$ so that $\pi^{i}=\pi^{b}$, for all $i \in I_{B}$, and

$$
\frac{\pi_{\omega}^{b} R_{\omega}}{q_{\omega}}=R, \text { for all } \omega \in S
$$

Condition (3) implies the following fact.

Fact $1 . \pi^{b}$ and $R$ can be inferred from $\left(q_{\omega} / R_{\omega}\right)_{\omega \in S}$. For all $\omega \in S$,

$$
\pi_{\omega}^{b}=\frac{q_{\omega} / R_{\omega}}{Q} \text { and } R=\frac{1}{Q} \text {, where } Q \equiv \sum_{\omega \in S} \frac{q_{\omega}}{R_{\omega}} .
$$

Proof. $1=\sum_{\omega \in S} \pi_{\omega}^{b}=\sum_{\omega \in S} R q_{\omega} / R_{\omega}$ and $\pi_{\omega}^{b}=\frac{q_{\omega}}{R_{\omega}} R=\frac{q_{\omega} / R_{\omega}}{Q}$. 
This shows how financial market data fully reveal the risk assessment of the market. Yet, there is no guarantee that the market measures the risky fundamentals in a perfect way 16 The assessment of $\pi^{*}$ by the financial market may be distorted for two reasons: Accurate assessment may be unfeasible; or too little effort is spent on the inspection of fundamentals 17 The following assumption is imposed on possible distortions.

Assumption 1. For all $\omega \in S$,

$$
\pi_{\omega}^{b}=\pi_{\omega}^{*}\left(1+\epsilon_{\omega}\right)
$$

(Note that $\sum_{\omega \in S} \pi_{\omega}^{b}=1$ implies $\sum_{\omega \in S} \pi_{\omega}^{*} \epsilon_{\omega}=1-\pi_{S}^{*}, \pi_{S}^{*} \equiv \sum_{\omega \in S} \pi_{\omega}^{*}$. )

Firms have to finance their capital input by issuing bonds or securities. (There is no internal financing.) Risky technologies are financed by Arrow

\footnotetext{
${ }^{16}$ As stated already, specification (2) implies that $\left(\pi_{\omega}\right)_{\omega \in S}$ and $A$ can be inferred if $\left(A_{\omega}\right)_{\omega \in S}$ is known. Likewise $\left(A_{\omega}\right)_{\omega \in S}$ can be inferred from $\left(\pi_{\omega}\right)_{\omega \in S}$ and $A$. Incorrect beliefs about $\left(\pi_{\omega}^{*}\right)_{\omega \in S},\left(A_{\omega}^{*}\right)_{\omega \in S}$ and $A^{*}$ arise if the following two conditions hold: i) $A_{\omega}^{*}$ is improperly assessed for some $\omega$; ii) $\pi_{\omega}^{*}$ is improperly assessed, for some $\omega$, or the $A^{*}$ assessment is wrong.

${ }^{17}$ This paper does not provide any microfoundation of how financial agents collect and aggregate information. Let $T$ be the total amount of resources raised by the fees $\tau^{-}, \tau^{+}$. The financial sector can spend this resources on two activities: direct inspection of fundamentals $\left(T_{I}\right)$ and arbitrage trade $\left(T_{A}\right)$. Both activities are required for collecting and aggregating information; assume there is an optimal mix $\xi^{*}=T_{A} / T_{D}$. Actually, however, the resources may be allocated in an inefficient way. Or total resources $T$ are too scarce to allow accurate assessment of fundamentals even under optimal allocation $\xi^{*}$. For instance, if the measure of differentiated environments is large, the cost of acquiring and aggregating information may be high and risk assessment more erroneous (see Section 7 for further explanation of this argument.) One could also relate the error process $\epsilon_{\omega}$ to the principal limits of informational efficiency shown by Grossman and Stiglitz [1980].
} 
securities; robust technologies are financed by bonds. There is no asymmetry between firms and financial agents with respect to the information which type is financed with a given instrument.

Investing one unit of capital in technology $\tilde{A}_{s}$ requires to sell $1 / q_{\omega}$ units of security for $\omega=s$ in $t=0$, for which $R_{\omega} / q_{\omega}$ units have to be paid back if $\omega \in S$ is realised in $t=1$. According to (1) and (2), a firm $f$ that wants to run technology $\tilde{A}_{s}$ believes that in state $\omega$ the output generated by one unit of capital (invested into the technology) is $A_{\omega}^{f}=A^{f} / \pi_{\omega}^{f}$, where $f$ refers to $f$ 's belief about the respective fundamentals. As a consequence, capital demand $K_{\omega}$ for a technology specialized to $\omega$ is given by:

$$
K_{\omega}=\left\{\begin{array}{l}
\infty \quad \text { if } A^{f} / \pi_{\omega}^{f}>R_{\omega} / q_{\omega}, \\
\text { fully elastic at } A^{f} / \pi_{\omega}^{f}=R_{\omega} / q_{\omega}, \\
0 \quad \text { otherwise }
\end{array}\right.
$$

This implies the following fact.

Fact 2. Specialized technologies can only be financed with Arrow-securities.

Moreover, $\frac{A^{f}}{\pi_{\omega}^{f}}=\frac{R_{\omega}}{q_{\omega}}$ if and only if:

$$
\pi_{\omega}^{f}=\pi_{\omega}^{b} \quad \text { for all } \omega \in S \text {, and } A^{f}=R(=1 / Q) .
$$

(In the following superscripts $f$ and $b$ are omitted.)

Proof. According to (3), $\frac{R_{\omega}}{q_{\omega}}=\frac{R}{\pi_{\omega}^{b}}$. Thus, $\frac{A^{f}}{\pi_{\omega}^{f}}=\frac{R_{\omega}}{q_{\omega}}$ is equivalent to $\pi_{\omega}^{b}=$ $\pi_{\omega}^{f} R / A^{f}$. Summing over $\omega$ gives us $1=R / A^{f}$ and thus $\pi_{\omega}^{b}=\pi_{\omega}^{f}$. Moreover, according to (4), $R=1 / Q$. 
In an analogous way, we have18: Capital demand for robust technologies is fully elastic at

$$
r=a^{*} .
$$

Since capital demand by firms is fully elastic, the capital inputs in future production possibilities are determined by the volume and the structure of aggregate savings.

\section{Households and savings}

In $t=0$ the economy is endowed with a resource $Y_{0}$ distributed over a mass $N$ of households. Let $y_{0}^{i}$ be the endowment of household $i$. Part of the endowment, $c_{0}^{i}$, is consumed, the other part, denoted by $b_{i}$, is saved. The saving is done partly by purchasing a portfolio of Arrow securities, $\left(z_{\omega}^{i}\right)_{\omega \in S}$, and partly by buying bonds, $l_{i}$. The income from saving, resulting in $t=1$, is fully spent on consumption $c_{\omega}^{i}$. For any $\omega \in S$, the effective sum available for spending may be disturbed by an idiosyncratic process $e_{\omega}^{i}$ with $\sum_{\omega \in S} \pi_{\omega}^{*} e_{\omega}^{i}=$ 0. In sum, conditional on the financial instruments offered by the financial sector, household $i$ faces the following budget constraints:

$$
\begin{aligned}
c_{0}^{i} & =y_{0}^{i}-b_{i}, \\
b_{i} & =\sum_{\omega \in S} q_{\omega} z_{\omega}^{i}+l_{i}, \\
c_{\omega}^{i} & = \begin{cases}R_{\omega}^{h} z_{\omega}^{i}+r_{h} l_{i}+e_{\omega}^{i}, & \text { if } \omega \in S, \\
r_{h} l_{i} & \text { otherwise. }\end{cases}
\end{aligned}
$$

\footnotetext{
${ }^{18}$ Financing a robust technology with $\omega$-securities would mean that the firm has to pay back $\frac{R_{\omega}}{q_{\omega}}=\frac{A}{\pi_{\omega}}>A$ if $\omega \in S$ is realised; the actual return though is $a^{*}<A$.
} 
Households have logarithmic intertemporal preferences with a discount $\delta \in$ $[0,1]$ on the future. The perception of and the reasoning about the future follows the structure described in Section 2, Let $\pi^{i}=\left(\pi_{\omega}^{i}\right)_{\omega \in S}$ and $0<\mu_{i}<1$ be the beliefs of household $i$ about $\pi^{*}$ and $\mu^{*}$, respectively 19 For a mixed portfolio with both saving in bonds and saving in risky assets we have to impose the condition

$$
\frac{r_{h}}{R_{h}}<\mu_{i}<1
$$

where $R_{h} \equiv \frac{1-\tau^{+}}{Q}$.

The household's saving and portfolio choice is given by the program

$$
\underset{b_{i},\left(z_{\omega}^{i}\right)_{\omega \in S}, l_{i}}{\operatorname{ax}} E U=\log \left(c_{0}^{i}\right)+\delta\left[\mu_{i} \sum_{\omega \in S} \pi_{\omega}^{i} \log \left(c_{\omega}^{i}\right)+\left(1-\mu_{i}\right) \log \left(r_{h} l_{i}\right)\right]
$$

subject to (8). As shown in the Appendix, this program leads to the following saving and consumption plans.

Proposition 1. For a household with beliefs $\left(\pi_{\omega}^{i}\right)_{\omega \in S}, \mu_{i}$,

a) the optimal saving is given by:

$$
\begin{aligned}
& b_{i}=\frac{\delta y_{0}^{i}-\tilde{E} e^{i}}{1+\delta} \\
& l_{i}=\left(1-\mu_{i}\right) \frac{b_{i}+\tilde{E} e^{i}}{1-r_{h} / R_{h}} \\
& \sum_{\omega \in S} q_{\omega} z_{\omega}^{i}=b_{i}-l_{i}
\end{aligned}
$$

with $R_{h} \equiv \frac{1-\tau^{+}}{Q}=\left(1-\tau^{+}\right) R$ and $\tilde{E} e^{i} \equiv \frac{1}{1-\tau^{+}} \sum_{\omega \in S} \frac{q_{\omega}}{R_{\omega}} e_{\omega}^{i}$.

\footnotetext{
${ }^{19}$ If $i$ has correct beliefs, $\mu_{i}=\mu^{*} \sum_{\omega \in S} \pi_{\omega}^{*} \leq \mu^{*}$. If $i$ assesses the measure $\mu^{*}$ correctly and otherwise follows the beliefs conveyed by the financial market, then $\mu_{i}=\mu^{*}$, as $\sum_{\omega \in S} \pi_{\omega}=1$. In general, $\mu_{i}$ can adopt any value between zero and one.
} 
b) The planned individual consumption levels are:

$$
c_{\omega}^{i}= \begin{cases}\mu_{i} \frac{\pi_{\omega}^{i}}{\pi_{\omega}} R_{h}\left(b_{i}+\tilde{E} e^{i}\right), & \text { if } \omega \in S \\ r_{h} l_{i} & \text { otherwise }\end{cases}
$$

Thus, financial markets promise to fully smooth consumption across $\omega \in S$. Moreover, a consumer fully bears the risk resulting from deviations of his or her beliefs $\pi_{\omega}^{i}$ from $\pi_{\omega}$ - the beliefs conveyed by the financial product characteristics and their prices 20 As equation (11) shows us, $c_{\omega}^{i}$ is fully insured on $S$ if and only if $\pi_{\omega}^{i}=\pi_{\omega}$. According to (4), the consumer can infer $\pi_{\omega}$ from $\left(q_{\omega}\right)_{\omega \in S}$ and $\left(R_{\omega}\right)_{\omega \in S}$ and eliminate this risk by adjusting $\pi_{\omega}^{i}$ to $\pi_{\omega}$. If consumer $i$ is insecure about $\pi_{\omega}^{i}$ he or she will do so. If however, $i$ is convinced that $\pi_{\omega}^{i}$ is closer to the true value than $\pi_{\omega}$, then the returns $R_{\omega}^{h} / q_{\omega}=R_{h} / \pi_{\omega}$ are considered as distorted and he or she plans to consume less than financial markets suggest, if $\pi_{\omega}^{i}<\pi_{\omega}$, and more, if $\pi_{\omega}^{i}>\pi_{\omega}$. Clearly, the households also pay the costs of unreliable risk and productivity assessment by the financial market. If $R \neq A^{*}$ or $\pi_{\omega} \neq \pi_{\omega}^{*}$, actual pay-off, $A_{\omega}^{*}$, will deviate from promised pay-off $R_{\omega}$ and consumer plans will be deceived. Section 5 will analyze the deviations between planned and realised consumption in detail.

Finally, it is worth noticing that $e_{\omega}^{i}$ enters the saving decisions by its financial market valuations, $\tilde{E} e^{i}$. Thus, in general, both the structure of the portfolio $\left(l_{i}, b_{i}-l_{i}\right)$ and the level of savings, $b_{i}$, depend on the financial sector's beliefs about the future. To see how, we calculate $\tilde{E} e^{i}=\frac{1}{R_{h}} \sum_{\omega \in S} \pi_{\omega} e_{\omega}^{i}$, which for $S=S^{*}$ is equivalent to $\tilde{E} e^{i}=\frac{\operatorname{Cov}^{*}\left(\epsilon, e^{i}\right)}{R_{h}}$, where $\operatorname{Cov}^{*}\left(\epsilon, e^{i}\right) \equiv \sum_{\omega \epsilon S^{*}} \pi_{\omega}^{*} \epsilon_{\omega} e_{\omega}^{i}$ is the covariance of belief distortion and exogenous income shocks 21 If mar-

\footnotetext{
${ }^{20}$ This is consistent with no-arbitrage condition (3), because by assumption households do not participate in pure arbitrage trade.

${ }^{21}$ According to (4), $\tilde{E} e^{i}=\frac{1}{R_{h}} \sum_{\omega \in S} \pi_{\omega} e_{\omega}^{i}$, where $R_{h}=\frac{1-\tau^{+}}{Q}$ has been used. Now,
} 
kets believe that positive income shocks dominate, then the present value of exogenous future income is positive. As a consequence, the saving level declines and the portfolio structure shifts in favor of bonds, ceteris paribus. This effect is moderated, if due to euphoric beliefs about the productivity of risky technologies the promised pay-offs of risky assets are high; and enhanced if the beliefs are pessimistic. For a household with $\operatorname{Cov}^{*}\left(\epsilon, e^{i}\right)<0$, we have the opposite effects on the saving behavior. In the further analysis the channel $\tilde{E} e^{i}$ will be shut down due to the aggregation assumption I impose for simplicity reasons. Nonetheless, it is worth keeping in mind that, in general, financial market valuations also affect accumulation through the value assigned to exogenous future opportunities that are not generated by accumulation.

Before we turn to aggregation, I want to summarize the conditions for an equilibrium.

Definition 1. (Equilibrium). An economy with a financial sector-characterized by $S,\left(R_{\omega}\right)_{\omega \in S},\left(q_{\omega}\right)_{\omega \in S}, r$ and $\tau^{-}, \tau^{+}$- and a real sector - with firm beliefs $\left(A_{\omega}^{f}\right)_{\omega \in S}$ and household beliefs $\pi^{i}$ and $\mu^{i}-i$ in equilibrium in $t=0$, if the following conditions hold: a) $r=a^{*}$. b) $\left(R_{\omega}\right)_{\omega \in S},\left(q_{\omega}\right)_{\omega \in S}$ satisfy noarbitrage conditions (3) for beliefs $\left(\pi_{\omega}\right)_{\omega \in S}$ and $R$ which are consistent with (6). c) For all households $i$, savings decisions $b^{i}, l^{i},\left(z_{\omega}\right)_{\omega \in S}$ and consumption plans $\left(c_{\omega}^{i}\right)_{\omega \in S}$ satisfy optimality conditions (10) and (11).

Future production possibilities are determined by the aggregate investment levels. Since under equilibrium conditions capital demand by firms is fully elastic, equalization of aggregate saving and investment is automatically $\overline{\sum_{\omega \in S} \pi_{\omega} e_{\omega}^{i}=\sum_{\omega \in S} \pi_{\omega}^{*} e_{\omega}^{i}+\sum_{\omega \in S}} \pi_{\omega}^{*} \epsilon_{\omega} e_{\omega}^{i}$, where $\sum_{\omega \in S} \pi_{\omega}^{*} e_{\omega}^{i}=0$ by assumption. 
guaranteed. In $t=1$, no actions can be taken and households are exposed to the consequences of the actions set in $t=0$ and the environment realised in $t=1$.

Provided that $b_{i}>0$ and $l_{i}>0$ for all $i$, the equations in (10) and (11) can be easily aggregated if the following assumption is made.

Assumption 2. (a) There exists a household $h$ so that for almost all $i \in N$ : $\mu_{i}=\mu_{h}$ and $\pi_{\omega}^{i}=\pi_{\omega}^{h}$. (b) For all $\omega \in S, \int_{N} e_{\omega}^{i} d i=0$.

Under this assumption we obtain from (10) for total savings, $B$, savings in bonds, $L$, and savings in state-contingent securities.22

$$
\begin{aligned}
& B=\frac{\delta}{1+\delta} Y_{0}, \\
& L=\frac{1-\mu_{h}}{1-\rho_{h}} B, \\
& B-L=\frac{\mu_{h}-\rho_{h}}{1-\rho_{h}} B,
\end{aligned}
$$

where $\rho_{h} \equiv \frac{r_{h}}{R_{h}}$, which can also be expressed in the form

$$
\rho_{h}=r Q / \tau, \quad \tau \equiv \frac{1-\tau^{+}}{1-\tau^{-}}
$$

For owning one unit of income in every state $\omega \in S$, one would need to buy $z_{\omega}=\frac{1}{R_{\omega}^{h}}$ units of each security. This requires $\frac{1}{1-\tau^{+}} \sum_{\omega \in S} \frac{q_{\omega}}{R_{\omega}}=\frac{Q}{1-\tau^{+}}$units of cash in $t=0$. Putting this into the bond would give $\frac{r_{h} Q}{1-\tau^{+}}=r Q / \tau$ in each $\omega \in \Omega$. Thus, $r Q / \tau$ describes the terms of trade between having one unit of income if the future lies in $S$ or one unit of income for sure. Representation $\rho_{h}=r Q / \tau$ gives us the look at the world when we see it through the lens of the valuation by the financial markets. We can represent $\rho_{h}$ also in terms of ${ }^{22}$ Note that $\int_{N} \tilde{E} e^{i} d i=\tilde{E} \int_{N} e_{\omega}^{i} d i=0$ as $\int_{N} e_{\omega}^{i} d i=0$ by assumption. 
the productivity beliefs of banks and firms coordinated and communicated by the financial market. By using (6) and (7), we obtain

$$
\rho_{h}=\frac{a^{*}}{\tau A}
$$

This represents the look at the economy from the real perspective.

The third equation in (12) shows aggregate savings in form of securities. The allocation of $B-L$ on the various securities determines the capital input to firms available for a particular technology. Let $I_{\omega}$ denote the amount invested into security $\omega \in S$. It is given by $I_{\omega}=\int_{N} q_{\omega} z_{\omega}^{i} d i$. Solving the household's budget constraint (8) for $z_{\omega}^{i}$ and aggregating, we obtain

$$
Z_{\omega} \equiv \int_{N} z_{\omega}^{i} d i=\frac{1}{R_{\omega}^{h}}\left(C_{\omega}-r_{h} L\right)
$$

where, according to Assumption 2 and the first equation in (11),

$$
C_{\omega} \equiv \int_{N} c_{\omega}^{i} d i=\frac{\mu_{h} \pi_{\omega}^{h}}{\pi_{\omega}} R_{h} B
$$

Substituting (16) for $C_{\omega}$ and (12) for $L$ into (15) and multiplying by $q_{\omega}$, we have

$$
I_{\omega}=\pi_{\omega} \frac{\frac{\pi_{\omega}^{h}}{\pi_{\omega}} \mu_{h}\left(1-\rho_{h}\right)-\rho_{h}\left(1-\mu_{h}\right)}{1-\rho_{h}} B
$$

where $\frac{q_{\omega}}{R_{\omega}^{h}}=\frac{\pi_{\omega}}{R_{h}}$ has been used from (3).

$I_{\omega}$ is increasing in $\pi_{\omega}^{h} / \pi_{\omega}$. Although households play a passive role in the financial market, their beliefs can in principle have an influence on the structure of realised projects. A higher share of savings goes to technologies that perform well in states which households belief to be more likely than banks and firms do. Nonetheless, the transformation of resources to the future crucially depends on the risk and productivity assessment of financial markets, 
represented by $\pi$ and $\rho_{h}$. Even if households hold correct beliefs about fundamentals, they have to trade at the conditions provided by the market. If they are distorted, households can at best moderate the external effect of distortions by careful assessment of fundamentals on their own, for instance by some market independent institution. For eliminating the distortions, this institution would have to intervene in the financial market by doing arbitrage trade on the households' behalf - on top of coordinating their beliefs on correct fundamental values. More realistically, if there is no such collective coordination by market independent institutions, the average household will follow the beliefs that can be inferred from the market according to (4).

Assumption 3. For all $\omega \in S, \pi_{\omega}^{h}=\pi_{\omega}\left(=\frac{q_{\omega} / R_{\omega}}{Q}\right)$.

With this assumption, equation (17) reduces to

$$
I_{\omega}=\pi_{\omega}(B-L) \quad \text { for } \omega \in S \text {. }
$$

In an economy with no unmeasurable uncertainty and correct assessment of risks and productivities, aggregate accumulation in the presented framework coincides with the model of Acemoglu and Zilibotti (1997) if transactions costs for financial intermediation are absent 23 In contrast to their framework, in the model presented here - even under correctly priced securities - financial innovations are only productive as long as $S$ is a strict subset of $S^{*}$. Moreover, if based on unreliable information, financial innovations are distortive within $S$, too.

\footnotetext{
${ }^{23}$ Specify $S^{*}=\Omega=[0,1]$ with true risk measured by the uniform distribution. Moreover, set $S=[0, \mu], \pi_{\omega}=1 / \mu, \mu_{h}=\mu, \tau=1$ and define $\bar{R} \equiv \mu A$. Then, $\rho_{h}=\frac{r}{R} \mu$ so that (12) and (18) reduce to $L=\frac{\bar{R}(1-\mu)}{R-r \mu}, B-L=\frac{\mu(\bar{R}-r)}{R-r \mu}, I_{\omega}=\frac{\bar{R}-r}{R-r \mu}$.
} 


\section{$5 \quad$ Financial beliefs meet reality: Planned vs. realised consumption}

In $t=0$, household saving, $B$, is invested in risky technologies, $I_{\omega}, \omega \in S$, and robust technologies, $L$, respectively. This allocation is based on the valuation of future events, as reflected in the prices and pay-off promises of assets offered in the financial market and on the households' belief $\mu_{h}$. Thus, there are essentially two potential sources of misguided saving and investment decisions: wrong household beliefs with regard to the measure of insurable future events $\left(\mu_{h} \neq \mu^{*}\right)$; and a distorted return structure $R_{\omega} / q_{\omega}$, conveying wrong productivity and risk expectations $\left(\pi_{\omega} \neq \pi_{\omega}^{*}, R \neq A^{*}\right)$. As a consequence, households' consumption plans may not be sustained by reality. This section compares, at the aggregate level, for the different sources of distortions the optimal plans with the actually realised outcome.

\subsection{Planned consumption levels}

According to (11), (12) and (16), under Assumption 1 and 2, the consumption levels planned for $t=1$ aggregate to:

$$
C_{\omega}^{p}= \begin{cases}\mu_{h} R_{h} B \equiv C_{+}^{p}, & \text { if } \omega \in S \\ r_{h} L=\frac{1-\mu_{h}}{1-\rho_{h}} r_{h} B \equiv C_{-}^{p}, & \text { if } \omega \in \bar{S}\end{cases}
$$

This gives us for the ratio of consumption planned for the future with unmeasurable uncertainty, $\bar{S}$, relative to the future with measurable risk, $S$ :

$$
\frac{C_{-}^{p}}{C_{+}^{p}}=\frac{1-\mu_{h}}{\mu_{h}} \frac{\rho_{h}}{1-\rho_{h}} .
$$




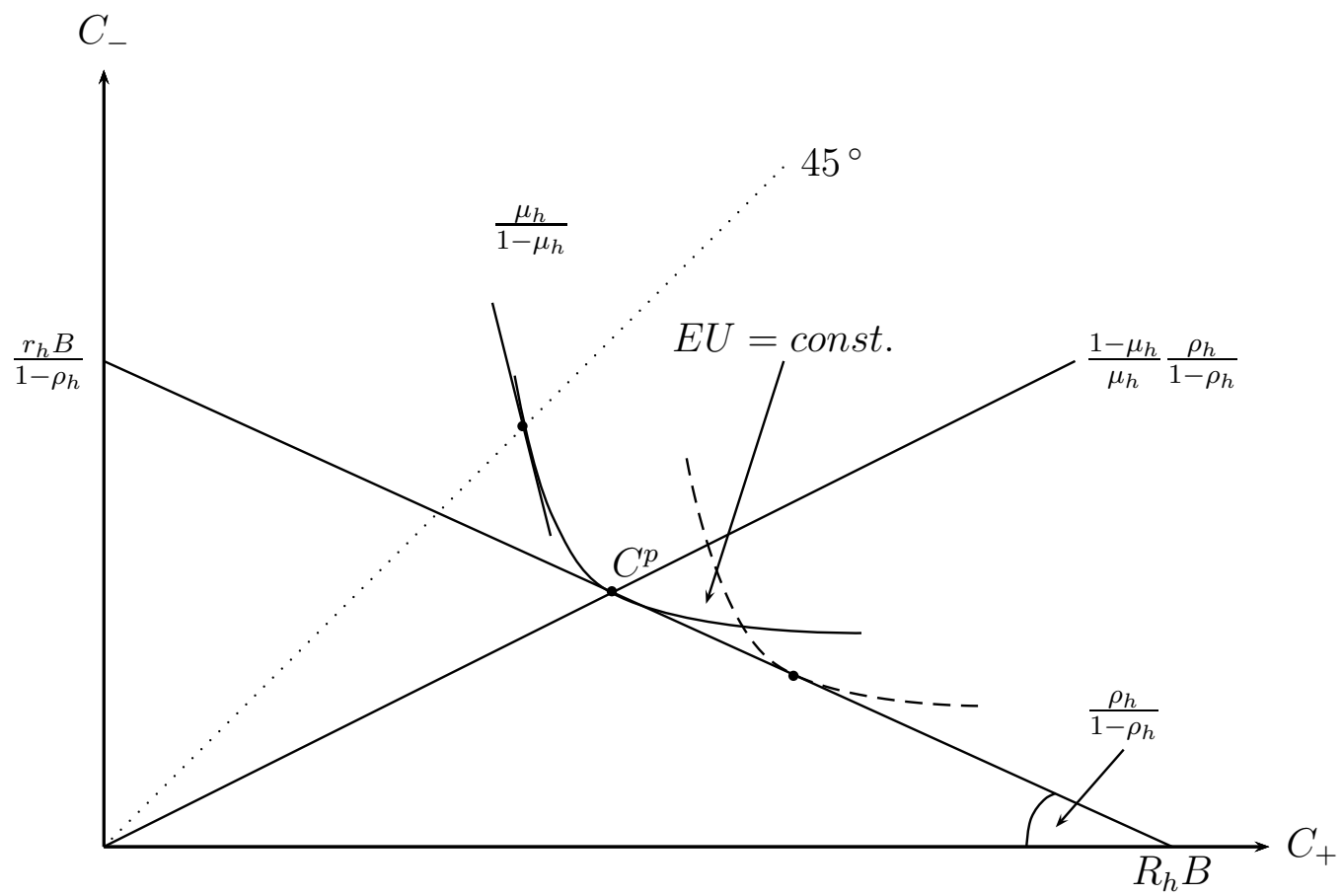

Figure 1: Consumption plan under $\mu_{h}, \rho_{h}$

For a graphical illustration it is useful to express also the households' intertemporal budget constraint in terms of $C_{+}, C_{-}$. Using (15), we can rewrite this constraint in the form: 24

$$
\rho_{h} C_{+}^{p}+\left(1-\rho_{h}\right) C_{-}^{p}=r_{h} B
$$

Figure1 shows expansion path (20) and budget constraint (21) in the $\left(C_{+}, C_{-}\right)$space. Intersection point $C^{p}$ represents the consumption plan resulting under $\mu_{h}$ and $\rho_{h}$. In addition, we define an aggregate utility index $E U\left(C_{+}, C_{-}\right) \equiv$ $\mu_{h} \log C_{+}^{p}+\left(1-\mu_{h}\right) \log C_{-}^{p}$ and calculate

$$
\left.\frac{d C_{-}^{p}}{d C_{+}^{p}}\right|_{E U=\text { const. }}=-\frac{\mu_{h}}{1-\mu_{h}} \frac{C_{-}^{p}}{C_{+}^{p}}
$$

\footnotetext{
${ }^{24}$ Note first: $B=\sum_{\omega \in S} q_{\omega} Z_{\omega}+L=\sum_{\omega \in S} \frac{q_{\omega}}{R_{\omega}^{h}} R_{\omega}^{h} Z_{\omega}+L$. Applying (15) we get from this: $B=\sum_{\omega \in S} \frac{q_{\omega}}{R_{\omega}^{h}}\left(C_{\omega}^{p}-C_{-}^{p}\right)+L=\frac{Q}{1-\tau^{+}}\left(C_{+}^{p}-C_{-}^{p}\right)+C_{-}^{p} / r_{h}$, which finally gives us (21). Note that $\rho_{h}=r_{h} / R_{h}=r Q / \tau$.
} 
For $C_{-}=C_{+}$, the absolute value of the slope of the iso- $E U$ curve is $\frac{\mu_{h}}{1-\mu_{h}}$. To the right of the $45^{\circ}$-line, the value diminishes - becoming tangential to the budget constraint at $C^{p}$. Therefore, aggregated consumption plans can be represented as optimum of a representative household which maximizes $E U\left(C_{+}, C_{-}\right)$subject to (21).

An immediate implication of (22) is that the representative indifference curve through a given point $C^{p}$ rotates clockwise if $\mu_{h}$ increases. Ceteris paribus, this shifts the optimal plan south-east; the expansion path rotates clockwise, too.

\subsection{Realised consumption levels}

In $t=1$, households receive the output of the production capacities created by their savings in $t=0$. Yet, part of their saving is absorbed by the costs of the financial sector. Total costs for the saving in bonds are given by $\left(r-r_{h}\right) L=r \tau^{-} L$, the value of which is at $t=0$ :

$$
T^{-}=\tau^{-} L
$$

Total costs for the saving in security $\omega \in S$ amount to $\left(R_{\omega}-R_{\omega}^{h}\right) Z_{\omega}=$ $\tau^{+} R_{\omega} Z_{\omega}$ in $t=1$. Discounting this by the return rate for this security, which is $R_{\omega} / q_{\omega}$, we get for the cost in $t=0$ the equivalent $\tau^{+} q_{\omega} Z_{\omega}$. Summing over $\omega \in S$, we have:

$$
T^{+}=\tau^{+}(B-L)
$$

Thus, aggregate capital inputs to firms are: $L^{n}=\left(1-\tau^{-}\right) L$ and $K_{\omega}=$ $\left(1-\tau^{+}\right) I_{\omega}, \omega \in S$. According to (11) and (2), they allow to produce in $t=1$ 
the following state-contingent output levels: 25

$$
X_{\omega}= \begin{cases}\frac{\bar{A}^{*}}{\pi_{\omega}^{*}} I_{\omega}+\bar{a}^{*} L, & \text { if } \omega \in S, \\ \bar{a}^{*} L, & \text { if } \omega \in \bar{S},\end{cases}
$$

where $\bar{A}^{*}=A^{*}\left(1-\tau^{+}\right)$and $\bar{a}^{*}=a^{*}\left(1-\tau^{-}\right)$. Note that true productivity levels, $A_{\omega}^{*}=A^{*} / \pi_{\omega}^{*}$, rather than beliefs are relevant for actual production. Using $C_{\omega}^{r}=X_{\omega}$ and substituting (18) for $I_{\omega}$ we obtain the realised consumption levels:

$$
C_{\omega}^{r}= \begin{cases}\frac{\pi_{\omega}}{\pi_{\omega}^{*}} \bar{A}^{*}(B-L)+\bar{a}^{*} L, & \text { if } \omega \in S, \\ \bar{a}^{*} L \equiv C_{-}^{r}, & \text { if } \omega \in \bar{S} .\end{cases}
$$

Comparison with (19) shows us immediately that $C_{-}^{r}=C_{-}^{p} \equiv C_{-}$. For $\omega \in S$, however, the situation is different. By using $\pi_{\omega}=\pi_{\omega}^{*}\left(1+\epsilon_{\omega}\right), C_{\omega}^{r}$ can be decomposed in the following way 26

$$
\begin{aligned}
& C_{\omega}^{r}=C_{+}^{r}+\epsilon_{\omega} \bar{A}^{*}(B-L), \\
& C_{+}^{r} \equiv C_{+}^{p}+\Delta,
\end{aligned}
$$

where $C_{+}^{p}$ is the planned consumption level given by (19) and $\Delta$ is defined by

$$
\Delta \equiv\left(1-\tau^{+}\right)\left(A^{*}-R\right)(B-L)
$$

We see that deviations of realised consumption from planned consumption can come through two channels: $\Delta$ and $\epsilon$.

\footnotetext{
${ }^{25}$ If $S^{*} \subset S$, then $X_{\omega}=0$ for $\omega \in S-S^{*}$ and all saving in securities $\omega \in S-S^{*}$ is lost. By assuming $S \subset S^{*}$ this drastic case was excluded.

${ }^{26}$ Note first that $C_{+}^{r}=C_{\omega}^{r}-\epsilon_{\omega} \bar{A}^{*}(B-L)=C_{-}+\bar{A}^{*}(B-L)$, according to (23). Substituting (12) for $L$ and $B-L$, we get from this $C_{+}^{r}-C_{+}^{p}=r_{h} B \frac{1-\mu_{h}+\left(\bar{A}^{*} / r_{h}\right)\left(\mu_{h}-\rho_{h}\right)-\left(\mu_{h} / \rho_{h}\right)\left(1-\rho_{h}\right)}{1-\rho_{h}}$, which reduces to $\Delta=$ $r_{h} B \frac{1-\mu_{h} / \rho_{h}+\left(A^{*} / R\right)\left(\mu_{h} / \rho_{h}-1\right)}{1-\rho_{h}}=\left(\frac{A^{*}}{R}-1\right) \frac{\mu_{h}-\rho_{h}}{1-\rho_{h}} \frac{r_{h} B}{\rho_{h}}$ and gives us (25).
} 
$\Delta$ reflects the deception (surprise) if promised pay-offs are not matched by the real outcome on average. We have:

$$
\begin{aligned}
& \Delta<0(=,>0) \text { if } R>A^{*}\left(=,<A^{*}, \text { resp. }\right) \\
& \text { and, if } \Delta \neq 0, \frac{\partial|\Delta|}{\partial \mu_{h}}>0 .
\end{aligned}
$$

Deception $\left(A^{*}<R\right)$ or surprise $\left(A^{*}>R\right)$ are magnified by optimistic views of the households about the "relative size" of the measurable part of future events $\left(\mu_{h}\right)$, as they induce households to save more in risky assets. Pessimistic views on $\mu_{h}$ moderate average deception and surprise.

The second source of deception or surprise is erroneous risk assessment $\left(\pi_{\omega}=\right.$ $\left.\frac{q_{\omega} / R_{\omega}}{Q}\right)$ conveyed by the return structure of risky assets. It makes realised consumption volatile within $S$, even though the events in $S$ are meant to be fully insured by the available securities. In the worst case, $C_{\omega}^{r}$ approaches $C_{-}$. Then the "deception" $C_{\omega}^{p}-C_{\omega}^{r}=\frac{\mu_{h}}{\rho_{h}} r_{h} B-C_{-}$is equal to $R_{h}(B-L)$. All saving in risky assets is lost. Section 6 and Section 7 will deepen the discussion of effects resulting from unreliable risk assessment.

Finally, it is worth noting that not all mistakes are revealed by reality ex post. In contrast to distorted financial prices and pay-offs, wrong household beliefs alone do not lead to deception or surprises. They remain undetected in our two-period framework. According to (25), $\Delta=0$ if $R=A^{*}$ regardless of the value of $\mu_{h}$. Nevertheless, wrong household beliefs affect the intertemporal allocation of resources. For an example, consider the case of overconfidence $\left(\mu_{h}>\mu^{*}\right)$. Compared to the first-best solution $C^{*}$, households are willing to accept too high a sacrifice of consumption possibilities in unmeasurable future environments $(\bar{S})$ in order to obtain high consumption levels in the measurable part $(S)$. Yet, if the productivity and risk valuation by financial 
markets is correct, no unhonored financial promises will reveal that households overestimate the extent of the risky future and underestimate the extent of true uncertainty.

\section{Size and quality of the financial sector}

The financial services are provided in $t=0$, when saving and investment decisions are made. For determining the share of the financial sector in $Y_{0}$, we have to calculate the present value of total costs charged to the real sector. They represent the income earned in the financial sector. The quality of the financial sector depends on two components: the degree of diversification that is made feasible by the provided financial products; and on how reliable their characteristics and prices convey information about risks and productivities.

\subsection{The size of the financial sector}

Since fee parameter $\tau^{-}$and $\tau^{+}$are exogenous in the presented model, total costs depend on the volume and structure of saving.27 As discussed in the previous section, we have in the aggregate $T^{-}=\tau^{-} L$ and $T^{+}=\tau^{+}(B-L)$, respectively. Total costs are thus $T=\tau^{+} B-\left(\tau^{+}-\tau^{-}\right) L$. Substituting (12) for $L$ and $B$, we obtain for the relative size of the financial sector in GDP,

\footnotetext{
${ }^{27}$ As should be obvious from the abstract character of the presented model, I have no intention to suggest concrete empirical patterns by the following comparative-static analysis. See Phillipon [2013] for a careful attempt to measure the long-run development of the US finance industry's share in GDP and its determinants empirically. This share has reached a new high in the last twenty five years.
} 
$T / Y_{0}:$

$$
\frac{\delta}{1+\delta}\left[\tau^{+}-\left(\tau^{+}-\tau^{-}\right) \frac{1-\mu_{h}}{1-\rho_{h}}\right] \equiv \chi .
$$

Obviously, the banking sector grows with the saving rate, $\frac{\delta}{1+\delta}$, and the charged fees $\tau^{-}, \tau^{+}$. The more interesting question is, how distortions affect the size of the financial sector relative to the real sector. They only matter if there is a differential in the costs of different forms of saving. Under the reasonable assumption that the costs of services for risky investments are higher than the cost of services for bonds, we have:

$$
\frac{\partial \chi}{\partial \mu_{h}}>0, \quad \frac{\partial \chi}{\partial \rho_{h}}<0
$$

For any given $\rho_{h}$, euphoric household beliefs - about the extent of measurable future events - blow up the financial sector, pessimistic beliefs let it shrink. Euphoric (pessimistic) assessment of risky projects, implying a decline (rise, resp.) of $\rho_{h}$, has similar effects.

Finally, it is worth noticing that a selective rise in $\tau^{+}$relative to $\tau^{-}$(for instance, if more complex financial products are offered) affects the size of the financial sector in two ways. On the one side, there is a direct positive effect. On the other side, there is a negative indirect effect through $\rho_{h}$. Differentiation establishes that for small differences $\tau^{+}-\tau^{-}$, the direct effect dominates, whereas the indirect negative effect dominates if $\tau^{+}-\tau^{-}$becomes large 28

\footnotetext{
${ }^{28} 1>d\left[\frac{\left(\tau^{+}-\tau^{-}\right)\left(1-\mu_{h}\right)}{1-\rho_{h}}\right] / d \tau^{+}$is equivalent to $\frac{1-\rho_{h}}{1-\mu_{h}}>1+\frac{\rho_{h}}{1-\rho_{h}} \frac{\tau^{+}-\tau^{-}}{1-\tau^{+}}$, where $\frac{\partial \rho_{h}}{\partial \tau^{+}}=\frac{\rho_{h}}{1-\tau^{+}}$ has been used. Since $\mu_{h}>\rho_{h}$, the left side of this inequality is larger than one. This proves $\partial \chi / \partial \tau^{+}>0$ if $\tau^{+}-\tau^{-}$is small.
} 


\subsection{The quality of the financial sector}

The economic functions of the financial market are to support the transformation of current resources into future output and to insure against risks. A possible indicator for the quality of the transformation function is the correct expectation of future consumption, given the aggregate volume of saved resources $(B)$ and their structure $(L, B-L)$. In an analogous way, we can take the correct variance of future consumption as indicator for the insurance function. For the correct expectation and variance of future output we have to weigh $C_{\omega}^{r}, \omega \in \Omega$, with the true measures $\pi_{\omega}^{*}$ for $\omega \in S^{*}$ and $\mu^{*}$ for $S^{*}$. Let $E^{*}\left[C^{r}\right]=\mu^{*} \sum_{\omega \in S} \pi_{\omega}^{*} C_{\omega}^{r}+\left[\mu^{*}\left(1-\pi_{S}^{*}\right)+\left(1-\mu^{*}\right)\right] C_{-}$denote the correct expectation of realised consumption and let $\operatorname{VAR}^{*}\left[C^{r}\right]=$ $\mu^{*} \sum_{\omega \in S} \pi_{\omega}^{*}\left(C_{\omega}^{r}-E^{*}\left[C^{r}\right]\right)^{2}+\left[\mu^{*}\left(1-\pi_{S}^{*}\right)+\left(1-\mu^{*}\right)\right]\left(C_{-}-E^{*}\left[C^{r}\right]\right)^{2}$ be the correct variance, where $\pi_{S}^{*} \equiv \sum_{\omega \in S} \pi_{\omega}^{*} . E^{*}\left[C^{r}\right]$ and $\mathrm{VAR}^{*}\left[C^{r}\right]$ are hypothetical values, which in general deviate from the values that households have in mind when making their saving plans 29 Using (23), we obtain 30

$$
E^{*}\left[C^{r}\right]=\mu^{*} \bar{A}^{*}(B-L)+\bar{a}^{*} L
$$

\footnotetext{
${ }^{29}$ The values are hypothetical because households have no possibility to observe the true values $A^{*}$ and $A_{\omega}^{*}=A^{*} / \pi_{\omega}^{*}$. Nonetheless, they can ask themselves: What outcomes - in terms of average and deviation from average - are to be expected if financial market conditions are based on wrong prerequisites? Such thought experiments may seem useless; a household cannot change the terms at which financial products are traded. Reflection about the consequences of model uncertainty serve a different purpose. They are useful for understanding the causes and consequences of imperfect information-processing in financial markets. Potentially, the understanding then leads to insights on how to improve the robustness of the financial system. In this spirit a policy rule is suggested in Section 7.

${ }^{30}$ Note $\sum_{\omega \in S} \pi_{\omega}=\sum_{\omega \in S} \pi_{\omega}^{*}\left(1+\epsilon_{\omega}\right)=1$
} 
The correct variance $\operatorname{VAR}^{*}\left[C^{r}\right]$ can be written in the form 31

$$
\operatorname{VAR}^{*}\left[C^{r}\right]=\mu^{*} D\left[\bar{A}^{*}(B-L)\right]^{2}
$$

with

$$
D \equiv \sum_{\omega \in S^{*}-S} \pi_{\omega}^{*}+\sum_{\omega \in S} \pi_{\omega}^{*} \epsilon_{\omega}^{2}+1-\mu^{*}
$$

Both true expectation and true variance rise with the volume of risky investment. Thus, distortions of the portfolio structure due to wrong household beliefs $\left(\mu_{h}\right)$ about the relative size of the measurable part of the future as well as distortions in the productivity assessment of risky technologies relative to the robust ones $(R / r)$ have straightforward effects.

A more interesting question is how financial innovations and the quality of risk assessment affect true expectation and true volatility of future consumption. To isolate these factors, we assume that households form correct beliefs so that $\mu_{h}=\mu^{*} \sum_{\omega \in S} \pi_{\omega}^{*}$. Thus, if financial innovations increase the measure of states covered by securities, the savings portfolio shifts towards risky assets, which increases $E^{*}\left[C^{r}\right]$ as well as $\operatorname{VAR}^{*}\left[C^{r}\right]$. At the same time, however, volatility is affected through factor $D$. The first term, $1-\pi_{S}^{*}, \pi_{S}^{*}=\sum_{\omega \in S} \pi_{\omega}^{*}$, is reduced if financial innovations expand the space spanned by securities. Yet, it may come with a cost, as shown by the second term, $\sum_{\omega \in S} \pi_{\omega}^{*} \epsilon_{\omega}^{2}$. This term captures the volatility increasing effect of unreliable risk assessment by financial markets. The unreliability effect counteracts the diversification effect. Finally, the third term of $D, 1-\mu^{*}$, shows the principle limits of diversification due to unmeasurable uncertainty in the sense of indistinguishable future environments.

\footnotetext{
${ }^{31}$ The proof is in the appendix.
} 


\section{Sound financial development under Knigh- tian uncertainty}

Instead of modeling "true" uncertainty as unmeasurable set of future environments, one can consider future events as uncertain if they are drawn from a measurable set with unknown measure. As discussed briefly in the introduction, this view corresponds to the approach pursued by studies on Knightian uncertainty. The view can be integrated in the presented framework by splitting $S^{*} \subset \Omega$ into subsets with varying precision of the risk distribution. For simplicity, let us set $S^{*}=\Omega$ and assume that true probabilities can be accurately assessed for $\omega \in S_{0}$, but for $\omega \in \bar{S}_{0}$ the true measure is unknown. That means, financial markets can provide reliable insurance for $S_{0}$, whereas outside $S_{0}$ insurance possibilities are based on unreliable information. More formally, there is a lower bound on the possible errors $\epsilon_{\omega}$ of beliefs about the probability of $\omega \in \bar{S}_{0}$. Whether and how far the beliefs conveyed by the characteristics and prices of financial products (contingent on $\omega \in \bar{S}_{0}$ ) deviate from these lower bound depends on the quality of financial markets. In the further analysis I assume that they accurately assess fundamentals wherever this is possible in principle. In particualr, I assume that average productivity is assessed correctly so that $R=A^{*}$ in the following.

Let $\left(\hat{\pi}_{\omega}\right)_{\omega \in \Omega}$ be the true probability measure on $\Omega$ and $S \subset \Omega$ be the set of states for which state-contingent securities are offered in the market. Then, $\mu(S)=\sum_{\omega \in S} \hat{\pi}_{\omega}$ is the true measure of $S ; \pi_{\omega}^{*}$ and $\pi_{\omega}$, which refer in the presented framework to conditional probabilities on $S$, are given by:

$$
\pi_{\omega}^{*}=\frac{\hat{\pi}_{\omega}}{\mu(S)} \text { and } \pi_{\omega}=\pi_{\omega}^{*}\left(1+\epsilon_{\omega}\right),
$$


where $\sum_{\omega \in S} \pi_{\omega}=1$ implies $\sum_{\omega \in S} \pi_{\omega}^{*} \epsilon_{\omega}=1-\sum_{\omega \in S} \pi_{\omega}^{*}=0$. This excludes systematic errors.

By assumption, for $\omega \in S_{0}$, the deviations of beliefs from true probabilities can be fully eliminated by careful risk assessment. In $S-S_{0}$ such deviations cannot be avoided. For $\omega \in S_{0}$, the productivity assessment is assumed to be accurate. We have $A_{\omega}^{*}=A^{*} / \pi_{\omega}^{*}$. This implies $\rho_{h}=\rho_{h}^{*}=\bar{a}^{*} / \bar{A}^{*}$. For $\omega \in \bar{S}_{0}$, neither $\hat{\pi}_{\omega}$ nor $A_{\omega}^{*}$ are known. The financial sector can be prudent and accept that there is no reliable informational basis for trading securities contingent on $\omega \in \bar{S}_{0}$. In this case, we have $S=S_{0}$ with $\pi_{\omega}=\pi_{\omega}^{*}=\hat{\pi}_{\omega} / \mu_{h}$ and $\mu_{h}=\sum_{\omega \in S_{0}} \hat{\pi}_{\omega}$ in the previous analysis. We can contrast this case with a scenario in which financial agents also provide state-contingent securities for a subset $S_{1}$ of $\bar{S}_{0}$, guessing, for $\omega \in S_{1}, \pi_{\omega}=\pi_{\omega}^{*}\left(1+\epsilon_{\omega}\right)$ and thus $A_{\omega}=A^{*} / \pi_{\omega}$. In this scenario, $S=S_{0} \cup S_{1}$ and $\pi_{\omega}^{*}=\hat{\pi}_{\omega} / \mu_{h}$ with $\mu_{h}=\mu_{0}+\mu_{1}$, $\mu_{j} \equiv \sum_{\omega \in S_{j}} \hat{\pi}_{\omega}, j \in\{0,1\}$. Under the assumption that risky assets involve higher intermediary fees, the size of the banking sector is larger under the second scenario compared to the first one. Moreover, as the previous analysis showed, a larger share of savings is allocated to risky projects, yielding on average a higher future output at the cost of uncertainty. The uncertainty hits the economy in $t=1$ by deviation of realised from planned consumption, and, if luck is bad, non-honored pay-off promises.

For a rigorous comparison we consider first the case of a prudent financial sector. I refer to this scenario by labeling saving and output variables with 
superscript zero. In this case, we have by (12) and (18):

$$
\begin{aligned}
& L^{0}=\frac{1-\mu_{0}}{1-\rho_{h}^{*}} B, \\
& B-L^{0}=\frac{\mu_{0}-\rho_{h}^{*}}{1-\rho_{h}^{*}} B, \\
& I_{\omega}^{0}=\pi_{\omega}^{*}\left(B-L^{0}\right) .
\end{aligned}
$$

In contrast, suppose that securities are provided for $\omega \in S_{1}$, too. If households trust in financial markets, their saving decisions lead to the following investment structure:

$$
\begin{aligned}
& L^{1}=\frac{1-\left(\mu_{0}+\mu_{1}\right)}{1-\rho_{h}^{*}} B, \\
& B-L^{1}=\frac{\left(\mu_{0}+\mu_{1}\right)-\rho_{h}^{*}}{1-\rho_{h}^{*}} B, \\
& I_{\omega}^{1}= \begin{cases}\pi_{\omega}^{*}\left(B-L^{1}\right) & \text { if } \omega \in S_{0}, \\
\pi_{\omega}\left(B-L^{1}\right) & \text { if } \omega \in S_{1},\end{cases}
\end{aligned}
$$

where superscript one is used to refer to the scenario with financial innovations for $\omega \in S_{1}$ based on unreliable information $\left(\pi_{\omega}=\pi_{\omega}^{*}\left(1+\epsilon_{\omega}\right)\right.$ and $\left.A_{\omega}=A^{*} / \pi_{\omega}\right)$.

Looking now at the realization of events in $t=1$, we see that deception of households becomes more likely. The chance that $\omega \in S_{1}$ is realised in $t=1$ is given by $\mu_{1}$. Thus with probability $\mu_{1}$ we end up in an environment in which realised consumption levels deviate from planned consumption levels. As shown in Section 5, for $\omega \in \bar{S}$, consumption plans $C_{-}^{p}$ are in line with realised consumption $C_{-}^{r}$. They are given by

$$
C_{-}=\bar{a}^{*} L^{1}
$$

Furthermore, plans and reality coincide if $\omega \in S_{0}$ is realised in $t=1$. Since $\rho_{h}=\rho_{h}^{*}=\bar{a}^{*} / \bar{A}^{*}$ and $\mu_{h}=\mu_{0}+\mu_{1}$ in the present context, consumption levels 
in $\omega \in S_{0}$, where $\pi_{\omega}=\pi_{\omega}^{*}$, are given by 32

$$
C_{+}=\left(\mu_{0}+\mu_{1}\right) \bar{A}^{*} B
$$

For $\omega \in S_{1}$, however, the realised consumption level deviates from the planned level $C_{+}^{p}$ by the term

$$
\epsilon_{\omega} \bar{A}^{*}\left(B-L^{1}\right)
$$

as shown by (24). (Note that $\Delta=0$ since $A=A^{*}$ in the present context). If $\epsilon_{\omega}<0$, firms cannot deliver the promised pay-off $R_{\omega}$. If $\epsilon_{\omega}>0$, there are unexpected gains.

Figure 2 illustrates the possible disturbances created by unfounded financial innovations. In the absence of such innovations $C_{0}$ would result in $t=1$. If securities are traded for $\omega \in S_{1}$, too, then household portfolios are adjusted so that $C_{1}$ results as planned consumption point in the $\left(C_{+}, C_{-}\right)$-space. Actually, however, some point in the bracketed interval around $C_{1}$ is realised. The size of the bracketed interval depends on the unreliability of risk and productivity assessment in $S_{1}$. One could argue that the error is relatively small as long as $S_{1}$ is a small extension beyond $S_{0}$; and increases, if a larger extension $S_{1}^{\prime}$ with $\mu_{1}^{\prime}>\mu_{1}$ is covered by financial innovations without reliable basis of information about true risks and productivities of technologies specialized in the new environments. This is illustrated by the expansion paths for different values of $\mu_{h}$. (With $\mu_{h}$ increasing the expansion path rotates downwards in the $\left(C_{+}, C_{-}\right)$-space.). Whatever the distribution of good luck and bad luck within the bracket around $C_{1}$ or $C_{2}$, there is a fundamental asymmetry. A realization of $C_{\omega}^{r}$ which falls short of the planned level is

\footnotetext{
${ }^{32}$ Using (31) in (23), we have, for $\omega \in S_{0}, C_{\omega}^{r}=B\left[\bar{A}^{*}\left(\mu_{h}-\rho_{h}^{*}\right)+\bar{a}^{*}\left(1-\mu_{h}\right)\right] /\left(1-\rho_{h}^{*}\right)$, which can be rewritten as $B \bar{A}^{*}\left[\mu_{h}-\rho_{h}^{*}+\rho_{h}^{*}\left(1-\mu_{h}\right)\right] /\left(1-\rho_{h}^{*}\right)$ and reduces to (33)
} 
not just a loss of consumption opportunities. It also means a loss of confidence in the system, because pay-off promises are broken. The two-period framework presented here is silent about what happens after the period in which the unreliability of financial products has been revealed. Therefore, the costs of a loss of confidence are outside the model. In any case, they have negative external effects beyond the foregone consumption in $t=1$. Therefore, the valuation of the gains of financial innovations beyond $S_{0}$ in terms of expected consumption against their unreliability is more than an individual consumer's trade-off under risk-aversion. It is a judgment about the reliability of the economic system.

Looking from this perspective on the results of the presented model, one can try to find a rule which relates the tolerable rate of financial innovations to real economic development. The following example illustrates how this could be done.

Let, for an ordered index set $\Gamma$ containing $\gamma=0,\left\{S_{\gamma}\right\}_{\gamma \in \Gamma}$ be a series of monotonously increasing subsets of $\Omega$ with $\hat{\pi}\left(S_{\gamma}^{\prime}-S_{\gamma}\right)>0$ for $\gamma^{\prime}>\gamma$. Then $\mu(\gamma) \equiv \sum_{\omega \in S_{\gamma}} \hat{\pi}_{\omega}$ is a monotonously increasing function of $\gamma$. Let $\pi_{\omega}^{*}=$ $\hat{\pi}_{\omega} / \mu(\gamma)$ be the true conditional probability of $\omega \in S_{\gamma}$. ( $\hat{\pi}$ denotes the true risk distribution over $\Omega$.) Assume that with increasing $\gamma$ the informational basis for assessing true risks becomes less and less reliable. Formally, $\pi_{\omega}=$ $\pi_{\omega}^{*}\left(1+\epsilon_{\omega}(\gamma)\right)$, where $\epsilon_{\omega}(\gamma)$ is an error process satisfying $\sum_{\omega \in S_{\gamma}} \pi_{\omega}^{*} \epsilon_{\omega}(\gamma)=0$ and the following assumption.

Assumption 4. ("Weakening experience base"). $\sigma_{\epsilon}^{2}(\gamma) \equiv \sum_{\omega \in S_{\gamma}} \pi_{\omega}^{*}\left[\epsilon_{\omega}(\gamma)\right]^{2}$ is increasing in $\gamma$, starting at $\sigma_{\epsilon}^{2}(0)=0$ and approaching $\bar{\sigma}_{\epsilon}^{2}$.

Assumption 4 means there is a terrain $S_{0}$ in which risks can be assessed 


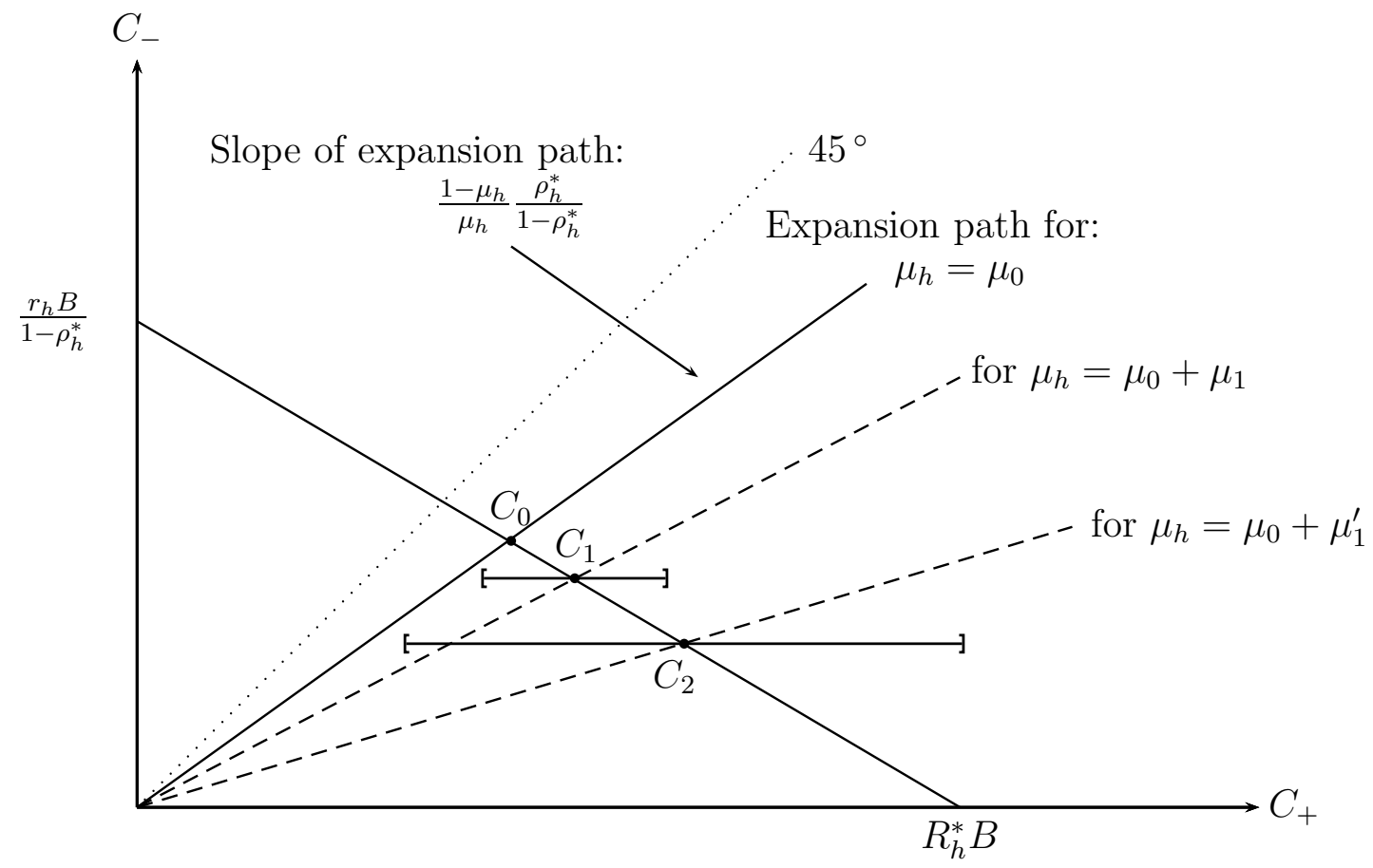

Figure 2: Insecurity generated by unreliable financial innovations $\left(\mu_{1}^{\prime}>\mu_{1}>0\right)$

accurately. The farther we move away from this terrain, the less reliable is the informational basis for risk assessment. To be specific, one could use the world GDP as a proxy for the accumulated experience in the past.

Suppose now that the frontier of financial innovations stands at some $\gamma \geq 0$, that is, state-contingent financial products are traded for all $\omega \in S_{\gamma}$. Denote by $\sigma_{C}^{2}(\gamma)$ the variance of consumption in $S_{\gamma}$. According to (24), this variance is proportional to $\sigma_{\epsilon}^{2}(\gamma)$. We have:

$$
\sigma_{C}^{2}(\gamma)=\left[\bar{A}^{*} \frac{\mu(\gamma)-\rho_{h}^{*}}{1-\rho_{h}^{*}} B\right]^{2} \sigma_{\epsilon}^{2}(\gamma)
$$

The planned consumption in $S_{\gamma}$ also increases with $\gamma$. According to (19),

$$
C_{+}^{p}=\mu(\gamma) \bar{A}^{*} B
$$


As mentioned previously, volatility $\sigma_{C}^{2}$ is not just a risk generated by nature; it comes from the expansion of the set of state-contingent financial products and reveals a mismatch between real possibilities and the possibilities promised by the financial market 33 Since deception of promises undermine confidence in the financial system (and can provoke severe crises) 34 , a society may agree that $\sigma_{C}^{2}$ should be kept in some tolerable relationship to the plans based on the promises. Since this comes at a cost, societies may accept more or less deception risk. I call this the "crisis tolerance" of a society 35 Formally, the tolerance can be defined by the following criterion: A society with crisis tolerance $\beta$ wishes that

$$
\sigma_{C}^{2}(\gamma) \leq \beta C_{+}^{p}
$$

Applying this criterion, we obtain the following result.

Proposition 2. (Policy rule). Under Assumption 4, for each $\beta<\bar{A}^{*} B \bar{\sigma}_{\epsilon}^{2}$, there exists a frontier $\bar{\gamma}(\beta)$ so that society's tolerance bound (37) is guaranteed if and only if $\gamma \leq \bar{\gamma}(\beta)$ (with strict inequality if $\bar{\gamma}(\beta) \notin \Gamma$ ). The frontier $\bar{\gamma}(\beta)$ has the following properties: $\bar{\gamma}(0)=0$ and $\frac{d \bar{\gamma}(\beta)}{d \beta}>0$.

Proof. With (35) and (36) inequality (37) becomes

$$
\sigma_{\epsilon}^{2}(\gamma) \leq \beta \frac{\mu(\gamma)}{\left(\mu(\gamma)-\rho_{h}^{*}\right)^{2}} \frac{\left(1-\rho_{h}^{*}\right)^{2}}{\bar{A}^{*} B}
$$

\footnotetext{
${ }^{33}$ Note that realization of $C_{-}$, if $\omega \in \bar{S}_{\gamma}$, generates no deception since realised consumption matches the plan. For $\bar{S}_{\gamma}$ no diversification possibilities were promised by the market and households knew that future consumption will be moderate outside $S_{\gamma}$.

${ }^{34}$ Crises are "situations in which 'a great number of merchants and traders at once either have, or apprehend that they shall have, a difficulty in meeting their engagements' ...” (Schumpeter [1954, 1959], p. 747 - quoting John Stuart Mill).

${ }^{35} \mathrm{I}$ use this label to avoid confusion with the notion "uncertainty aversion" in Gilboa and Schmeidler [1989] which is related to Bewley's [2002] "inertia assumption". For $\beta=0$ only $S_{\gamma}=S_{0}$ would be tolerable.
} 
The left side of this inequality is an increasing function of $\gamma$, starting at $\sigma_{\epsilon}^{2}(0)=0$ and approaching $\bar{\sigma}_{\epsilon}^{2}$ (Assumption 4). The right side of the equation is positive for $\gamma=0$ and declines with $\gamma$ towards $\frac{\beta}{A^{*} B}$ if $\mu(\gamma)=1$ is approached. Thus, a unique interior intersection point $\bar{\gamma}(\beta) \in \mathbb{R}_{+}$exists as long as $\beta<\bar{\sigma}_{\epsilon}^{2} A^{*} B$. If $\bar{\gamma}(\beta) \notin \Gamma$, then, for any $\gamma \in \Gamma$, condition (37) holds if $\gamma<\bar{\gamma}(\beta)$ and does not hold if $\gamma>\bar{\gamma}(\beta)$. The properties of $\bar{\gamma}(\beta)$ are an immediate consequence of the fact that the right-hand side of inequality (38) rises with $\beta$, starting at zero for $\beta=0$.

If GDP is taken as proxy for the reliable experience base, Proposition 2 suggests to tie the financial innovation dynamics down to the long-run growth rate 36 Policies for implementing such ties would complement regulations of volumes and frequencies of financial trading on a given set of financial products. In the approach presented here, the latter regulations affect the allocation of the financial sector's resources, $T$, on direct inspection and arbitrage trade. This should reduce potential inefficiencies within the financial sector and bring the errors contained in the prices and pay-offs of financial products closer to the bounds imposed by principal limits of knowledge about the future. A policy rule based on Proposition 2 would limit the unavoidable errors arising from overconfidence in the possibilities of financial markets to generate knowledge about the future.

\footnotetext{
${ }^{36}$ This would be analogous to monetary policy rules, which ultimately also are founded on the argument that excess money supply (through the channel of inflation) destroys the information-processing quality of markets.
} 


\section{Conclusion}

What are the real fundamentals in a world in which objects are composed of (in the broad sense of the word) physical properties and the valuation of these properties by financial markets? This paper tried to disentangle the mixture of "men-made" and exogenous fundamentals. The endeavor was driven by the firm conviction that, if rationality has any meaning, economic analysis needs to reflect the principle limits of knowledge and perception with regard to the future. Basic principals of the proposed framework were the distinction between risk and uncertainty and a careful tracking of what agents know, what they do not know, what they know from market information and what they might know more or less by direct inspection of reality. The answer was different for different types of agents, depending on their roles, namely on whether they act as firm, as household or as financial agent.

The main message following from the analysis was that things can go wrong, due to bad luck, or because of sloppy evaluation of reality and careless dealing with uncertainty. In the first case, the economy experiences a fatal shock, which hurts but is no surprise in a world of incomplete knowledge. In the second case, the distortion is men-made and a crisis of confidence can emerge.

The paper did not provide any microfoundation of the inside of the financial sector; rather it focused on the consequences of the products and prices produced by the financial market for production in firms and consumption of households. According to the presented model, in a crisis households experience non-honored pay-off promises and deceived consumption plans, which reveal that the information conveyed by the financial market was based on 
unreliable assessment of future productivities and risks. Therefore, financial innovations expanding the space spanned by securities are not necessary a good thing. Missing markets may be better than unreliable ones. Essentially, two sources of financial market failures can be made responsible for household deception in the presented framework: First, the allocation of financial sector resources on collecting and aggregating information about risks and productivities of risky projects may be distorted. Second, financial innovations provide state-contingent securities for uncertain environments without reliable information about the measure of events or the real performance of projects in these environments. To account for the second problem, a policy rule was outlined in the last section, which attempts to bring the reliability of financial innovations in line with the crisis tolerance of a society.

A series of problems remained open. In particular, the inside of the financial sector was taken as a black box in this paper, which is silent on finance issues in a more narrow sense of the word. The bottom line was that these issues are complementary to the presented analysis. They concern the trading within the financial sector, which aggregates the information collected by the financial agents and coordinates their beliefs in the model. As mentioned, if financial sector resources employed in arbitrage trade are not aligned to the resources employed for collecting information from direct inspection of reality, the information communicated by financial product characteristics and prices to the households is unreliable.

Finally, learning from real market data was excluded in the presented twoperiod framework. This reflects in a radical way the fact that learning possibilities about future environments from markets data are limited. By extending the model to more than two periods, one could possibly substantiate 
a hypothesis about the frequency of crises. According to the uncertainty and knowledge structure defined in this paper, the learning about fundamentals in risky environments $\left(\pi^{*}\right.$ and $A_{\omega}^{*}$ in the model) depends on the number of observed realizations of events generated by a stationary stochastic risk and productivity process. If there is a structural break, or if financial innovations outgrow the speed of learning, then there is a danger of a crisis in the sense of this paper. In the first case, the learning has to start again. In the second case, we have to tame an excessive financial business. In contrast, the learning about the extent of risky environments compared to unmeasurable uncertainty $-S^{*}$ vs. $\Omega-S^{*}$ in the model - depends on the frequency of observations of $\omega \in S^{*}$ as opposed to $\omega \in \Omega-S^{*}$. The latter means, we have to experience bad luck with only robust technologies working properly. That is, we have to experience fatal shocks, in which the economy works at a low productivity but which are no surprise and not accompanied by deceived promises. 


\section{A Appendix}

\section{A.1 Optimal program of household $i$}

The first-oder conditions for $\max E U$ s.t. (8) are for $b_{i}, z_{\omega}^{i}$ and $l_{i}$, respectively:

$$
\begin{aligned}
& \frac{1}{y_{0}^{i}-b_{i}}=\lambda_{i}, \\
& \frac{\delta \mu_{i} \pi_{\omega}^{i}}{c_{\omega}^{i}} R_{\omega}^{h}=\lambda_{i} q_{\omega}, \quad \omega \in S, \\
& \delta \mu_{i} \sum_{\omega \in S} \frac{\pi_{\omega}^{i}}{c_{\omega}^{i}} r_{h}+\delta \frac{r_{h}\left(1-\mu_{i}\right)}{r_{h} l_{i}}=\lambda_{i},
\end{aligned}
$$

where $\lambda_{i}$ is the Langrange multiplier for constraint $\sum_{\omega \in S} q_{\omega} z_{\omega}^{i}+l_{i} \leq b_{i}$. Using (A.1B) we can rewrite (A.1C) in the form

$$
\lambda_{i} r_{h} \frac{Q}{1-\tau^{+}}+\frac{\delta\left(1-\mu_{i}\right)}{l_{i}}=\lambda_{i}
$$

with $Q \equiv \sum_{\omega \in S} \frac{q_{\omega}}{R_{\omega}}$.

With $R_{h} \equiv \frac{1-\tau^{+}}{Q}$ equation $(\underline{A .2})$ can be rewritten in the form

$$
l_{i}=\frac{\delta}{\lambda_{i}} \frac{1-\mu_{i}}{1-r_{h} / R_{h}}
$$

and (A.1B) together with budget constraint (8) for $c_{\omega}^{i}, \omega \in S$, gives us:

$$
\begin{aligned}
& z_{\omega}^{i}=\frac{\delta}{\lambda^{i}} \frac{\mu_{i} \pi_{\omega}^{i}}{q_{\omega}}-\frac{r_{h} l_{i}+e_{\omega}^{i}}{R_{\omega}^{h}} \\
& q_{\omega} z_{\omega}^{i}=\frac{\delta}{\lambda_{i}} \mu_{i} \pi_{\omega}^{i}-\left(r_{h} l_{i}+e_{\omega}^{i}\right) \frac{q_{\omega}}{R_{\omega}^{h}} \\
& \sum_{\omega \in S} q_{\omega} z_{\omega}^{i}=\frac{\delta}{\lambda_{i}} \mu_{i}-\frac{r_{h}}{R_{h}} l_{i}-\tilde{E} e^{i}
\end{aligned}
$$

with $\tilde{E} e^{i} \equiv \frac{1}{1-\tau^{+}} \sum_{\omega \in S} \frac{q_{\omega}}{R_{\omega}} e_{\omega}^{i}$. 
Substituting (A.4C) into the budget constraint $b_{i}=\sum_{\omega \in S} q_{\omega} z_{\omega}^{i}+l_{i}$, we get $b_{i}=l_{i}\left(1-\frac{r_{h}}{R_{h}}\right)+\frac{\delta}{\lambda_{i}} \mu_{i}-\tilde{E} e^{i}$. Substituting (A.3) for $l_{i}$, we have

$$
\frac{\delta}{\lambda_{i}}=b_{i}+\tilde{E} e^{i}
$$

This, (A.1a) and (A.3) give us

$$
\begin{aligned}
b_{i} & =\frac{\delta y_{0}^{i}-\tilde{E} e^{i}}{1+\delta}, \\
l_{i} & =\left(1-\mu_{i}\right) \frac{b_{i}+\tilde{E} e^{i}}{1-r_{h} / R_{h}} .
\end{aligned}
$$

Using then (A.5) in (A.1b) and $\frac{R_{\omega}^{h}}{q_{\omega}}=\frac{1-\tau^{+}}{\pi_{\omega} Q}$ from (41) and accounting for $R_{h} \equiv \frac{1-\tau^{+}}{Q}$, we obtain

$$
c_{\omega}^{i}=\left(b_{i}+\tilde{E} e^{i}\right) \mu_{i} \frac{\pi_{\omega}^{i}}{\pi_{\omega}} R_{h}
$$

Finally, according to the budget constraint for $c_{\omega}^{i}, \omega \notin S$,

$$
c_{\omega}^{i}=r_{h} l_{i}
$$

\section{A.2 Derivation of the $\operatorname{VAR}^{*}\left(C^{r}\right)$}

Use (23), (28) and notation $X_{+} \equiv \bar{A}^{*}(B-L), \pi_{S}^{*} \equiv \sum_{\omega \in S} \pi_{\omega}^{*}$, to calculate $\left(C_{\omega}^{r}-E^{*}\left[C^{r}\right]\right)^{2}=\left(1+\epsilon_{\omega}-\mu^{*}\right)^{2} X_{+}^{2}$ for $\omega \in S$, and $\left(C_{\omega}^{r}-E^{*}\left[C^{r}\right]\right)^{2}=\left(\mu^{*} X_{+}\right)^{2}$ for $\omega \notin S$. Thus,

$$
\begin{aligned}
\operatorname{VAR}^{*}\left[C^{r}\right] & =\mu^{*}\left[\sum_{\omega \in S} \pi_{\omega}^{*}\left(1+\epsilon_{\omega}-\mu^{*}\right)^{2} X_{+}^{2}+\left(1-\pi_{S}^{*}\right)\left(\mu^{*} X_{+}\right)^{2}\right]+\left(1-\mu^{*}\right)\left(\mu^{*} X_{+}\right)^{2} \\
& =\mu^{*} X_{+}^{2}\left\{\sum_{\omega \in S} \pi_{\omega}^{*}\left(1+\epsilon_{\omega}-\mu^{*}\right)^{2}+\left[\mu^{*}\left(1-\pi_{S}^{*}\right)+\left(1-\mu^{*}\right)\right] \mu^{*}\right\} \\
& =\mu^{*} X_{+}^{2}\left[\sum_{\omega \in S} \pi_{\omega}^{*}\left(1+\epsilon_{\omega}-\mu^{*}\right)^{2}+\left(1-\mu^{*} \pi_{S}^{*}\right) \mu^{*}\right]
\end{aligned}
$$


In a next step, check that

$$
\begin{aligned}
\sum_{\omega \in S} \pi_{\omega}^{*}\left(1+\epsilon_{\omega}-\mu^{*}\right)^{2} & =\sum_{\omega \in S} \pi_{\omega}^{*}\left[1+2 \epsilon_{\omega}\left(1-\mu^{*}\right)+\epsilon_{\omega}^{2}-2 \mu^{*}+\mu^{*^{2}}\right] \\
& =\pi_{S}^{*}+2\left(1-\pi_{S}^{*}\right)\left(1-\mu^{*}\right)+\sum_{\omega \in S} \pi_{S}^{*} \epsilon_{\omega}^{2}-\pi_{S}^{*}\left(2 \mu^{*}-\mu^{*^{2}}\right) \\
& =2\left(1-\pi_{S}^{*}\right)\left(1-\mu^{*}\right)+\sum_{\omega \in S} \pi_{S}^{*} \epsilon_{\omega}^{2}+\pi_{S}^{*}\left(1-\mu^{*}\right)^{2}
\end{aligned}
$$

where $\sum_{\omega \in S} \pi_{\omega}^{*} \epsilon_{\omega}=1-\pi_{S}^{*}$ has been used.

Thus, the square-bracketed term in the last equation of $\mathrm{VAR}^{*}\left[C^{r}\right]$ reduces to $D$, as the following calculation shows:

$$
\begin{aligned}
& 2\left(1-\pi_{S}^{*}\right)\left(1-\mu^{*}\right)+\sum_{\omega \in S} \pi_{\omega}^{*} \epsilon_{\omega}^{2}+\pi_{S}^{*}\left(1-\mu^{*}\right)^{2}+\left(1-\mu^{*} \pi_{S}^{*}\right) \mu^{*} \\
& =\sum_{\omega \in S} \pi_{\omega}^{*} \epsilon_{\omega}^{2}+\left(1-\mu^{*}\right)\left(1-\pi_{S}^{*}+1-\mu^{*} \pi_{S}^{*}\right)+\mu^{*}\left(1-\mu^{*} \pi_{S}^{*}\right) \\
& =\sum_{\omega \in S} \pi_{\omega}^{*} \epsilon_{\omega}^{2}+1-\pi_{S}^{*}+1-\mu^{*}=D .
\end{aligned}
$$




\section{References}

Acemoglu, Daron and Fabrizio Zilibotti (1997), "Was Promotheus unbound by chance? Risk, diversification, and growth", Journal of Political Economy 105(4), 709-751.

Angeletos, George-Marios and Iván Werning (2006), "Crises and prices: Information aggregation, multiplicity, and volatility", American Economic Review 36(5), 1720-1736.

Bai, Jennie, Philippon, Thomas and Alexi Savov (2013), "Have financial markets become more informative?", Working Paper NYU.

Bewley, Truman F. (2002), "Knightian decision theory. Part I", Decision in Economics and Finance 25, 79-110.

Bond, Philip, Edmans, Alex and Itay Goldstein (2012), "The real effects of financial markets", Annual Review of Financial Economics 4, 339-360.

Borio, Claudio (2012), "The financial cycle and macroeconomics: What have we learnt?", BIS Working Papers No.395.

Brunnermeier, Markus K., and Yuliy Sannikov (2014), "A macroeconomic model with a financial sector", American Economic Review 104(2), 379-421.

Caballero, Ricardo (2010), "Macroeconomics after the crisis: Time to deal with the pretence-of-knowledge syndrome", Journal of Economic Perspectives $24(4), 85-102$.

Cerreia-Vioglio, Simone, Maccheroni, Fabio, Marinacci, Massimio and Luigi Montrucchio (2013), "Ambiguity and robust statistics", Journal of Economic Theory 148, 974-1049. 
Diamond, Peter A. (1967), "The role of a stock market in a general equilibrium model with technological uncertainty", American Economic Review 57, 759-776.

Ellsberg, Daniel (1961), "Risk, ambiguity, and the Savage axioms", Quarterly Journal of Economics 75(4), 643-669.

Fama, Eugene F. (1970), "Efficient capital markets: A review of theory and empirical work", Journal of Finance 25(2), 383-417.

Freixas, Xavier, and Jean-Charles Rochet (1998), Microeconomics of banking, Second edition 2008, Cambridge/Mass.:MIT Press.

Geanakoplos, John (2010), "The leverage cycle", Cowles Foundation Paper No.1304.

Gilboa, Itzhak and David, Schmeidler (1989), "Maxmin expected utility with non-unique prior", Journal of Mathematical Economics 18, 141-153.

Greenwood, Robin and David Scharfstein (2013), "The growth of finance", Journal of Economic Perspectives 27(2), 3-28.

Grossman, Sanford J. and Joseph E. Stiglitz (1976), "Information and competitive price systems", American Economic Review 66(2), 246-253.

Grossman, Sanford J. and Joseph E. Stiglitz (1980), "On the impossibility of informationally efficient markets", American Economic Review 70(3), 393-408.

Hansen, Lars Peter, and Thomas J. Sargent (2008), Robustness, Princeton University Press. 
Hayek, Friedrich A. (1945), "The use of knowledge in society", American Economic Review 35(4), 519-530.

Hirshleifer, Jack (1971), "The private and social value of information and the reward to inventive activity", American Economic Review 61(4), 561574.

Keynes, John M. (1937), "The general theory of employment", Quarterly Journal of Economics 51(February), 209-223.

Laski, Kazimierz (1987), Kalecki, Michat. In: J.Cadwell, M.Milgate and P.Newman (eds.), The New Palgrave, Vol.3, London et al: Macmillan Press. Magill, Michael, Quinzii, Martine and Jean-Charles, Rochet (2013), "A critique of shareholder value maximization", Swiss Finance Institute Research Paper No. 13-16.

Modica, Salvatore and Aldo Rustichini (1999), "Unawareness and partial information structures", Games and Economic Behavior 27, 265-298.

Morris, Stephen and Hyun Song Shin (1998), "Unique equilibrium in a model of self-fulfilling currency attacks", American Economic Review 88(3), 587-597.

Philippon, Thomas (2013), "Has the U.S. finance industry become less efficient? On the theory and measurement of financial intermediation", Working paper $N Y U$.

Schumpeter, Joseph A. (1954), History of economic analysis, edited by Elizabeth Boody Schumpeter, New York: Oxford University Press. Cited after Third printing 1959. 
Shin, Hyun Song (2007), "Risk and liquidity in a system context", Journal of Financial Intermediation 17, 315-329.

Solow, Robert (2008), "The state of macroeconomics", Journal of Economic Perspecives 22, 243-249. 